\title{
The Impact of Worker Bargaining Power on the Organization of Global Firms*
}

\author{
Juan Carluccio ${ }^{\dagger}$ and Maria Bas ${ }^{\ddagger}$
}

\begin{abstract}
Do variations in labor market institutions affect the cross-border organization of the firm? Using firm-level data on multinationals located in France, we show that firms are more likely to outsource the production of intermediate inputs to external suppliers when importing from countries with high worker bargaining power. This effect is stronger for firms operating in capital-intensive and differentiated industries. We propose a theoretical mechanism that rationalizes these findings. The fragmentation of the value chain weakens the workers' bargaining position, by limiting the amount of revenues that are subject to union extraction. The outsourcing strategy reduces the share of surplus that is appropriated by the union, which enhances the firm's incentives to invest. Since investment creates relatively more value in capital-intensive industries, increases in worker bargaining power are more likely to be conducive to outsourcing in those industries. Overall, our findings suggest that global firms choose their organizational structure strategically when sourcing intermediate inputs from markets where worker bargaining power is high.
\end{abstract}

Keywords: worker bargaining power, labor market imperfections, outsourcing, multinational firms.

JEL Classification: F14; F23; J5.

${ }^{*}$ We thank the editor and two anonymous referees for their insightful comments and suggestions. We thank Thierry Verdier for invaluable guidance. We have also benefited from discussions with Laura Alfaro, Pol Antràs, Pierre Cahuc, Maia Carluccio, Davin Chor, Arnaud Costinot, Matthieu Crozet, Karolina Eckholm, Thibault Fally, Lionel Fontagne, Juan Carlos Hallak, Christian Hellwig, Elhanan Helpman, Yannick Kalantis, Giordano Mion, Charles O'Donnell, Thierry Mayer, Andy Newman, Nathan Nunn, Gianmarco Ottaviano, Emanuel Ornelas, Diego Puga, Frederic Robert-Nicoud, Steve Redding, Gaston Schettino, Gregory Verdugo, Andreas Waldkrich, and seminar participants at the 2010 World Meeting of the Econometric Society and other venues where a previous version of this paper was presented. We are responsible for any remaining errors.

$\dagger$ Banque de France and University of Surrey. Corresponding author: 31, Rue Croix-des-Petits-Champs, 75001 Paris France.

Email: juan.carluccio@gmail.com. Phone: +33677357305. Fax: +33142926292.

${ }^{\ddagger}$ Centre d'études prospectives et d’informations internationales (CEPII). 


\section{Introduction}

The globalization process is characterized by increasing international specialization of production and the organization of firms' activities on a global scale. Around one-third of total trade takes place within multinational firms' boundaries, with developed countries posting an even larger proportion. Furthermore, trade in intermediate inputs has risen steadily in recent decades to become a key feature of the current international trade structure (Hummels et al., 2001). In this context, the study of global production networks naturally attracted a great deal of attention.

In this paper we ask how the cross-border organization of firms is affected by bargaining in the labor market. We are interested in the way the bargaining power of workers in host countries affects sourcing decisions by multinational firms. We present an empirical analysis based on a unique firm-level dataset on the sourcing modes of multinationals located in France. An important feature of these data is that they provide the proportion of intra-firm imports for each firm, seller-industry, and country-of-origin triplet. We use an index developed in Botero et al. (2004) that captures the power of workers by means of the extent to which industrial action is allowed by the law. Our results show that the bargaining power of workers in origin countries has a negative effect on the share of intra-firm imports. The effect is sizeable. The average share of intra-firm imports in the sample is $28 \%$. Take the countries with the highest (Italy) and lowest (Denmark) index value. ${ }^{1}$ If Italy's labor market institutions were equal to Denmark's, the average intra-firm exports to France would increase by $7.6 \%$. This figure rises to $12.8 \%$ when we run the regression on OECD countries alone.

Our results hold using more traditional measures of bargaining power such as union coverage, and they are robust to the inclusion of a large set of controls that have been shown to determine intra-firm trade shares. We also present within-country evidence based on the variation in unionization rates across US industries. Our estimations indicate that the negative correlation between the share of intra-firm imports and worker bargaining power increases with capital intensity, but only in the case of industries for which relationship-specific investments are substantial ("relationship-specific" industries), and thus for which the hold-up problem is relatively more important. We identify the relationship-specific industries in our data using the Rauch (1999) classification of commodities, following a strategy similar to that of Nunn (2007).

We motivate our empirical analysis with a simple model of outsourcing under incomplete contracts, to which we introduce labor market bargaining. In an upstream stage of production, an intermediate good is manufactured by workers, who bargain collectively on wages and employment. Downstream, the intermediate good is transformed into a final good by means of the firms' capital stock. The organizational decision is whether to keep the production of the component within the firm's boundaries or to outsource it to an independent supplier. A key assumption of the model is that, when operating an integrated facility, the final-good producer bargains with the union over the sharing of total profits. Conversely, when production of the component is outsourced, the supplier and the workers bargain over the profits of the subcontractor. Through this mechanism, outsourcing weakens the union's bargaining position. However, when subcontracting, the firm faces a risk of opportunistic behavior from the supplier. When union bargaining power is above a certain cutoff, the cost of running an integrated plant in terms of rent-sharing is large, and subcontracting is chosen. This cutoff value depends on the capital intensity of the production process. With specific capital, the firm faces a potential hold-up problem from the union (Grout, 1984). Outsourcing reduces exposure to ex-post worker opportunism because, in the bargain with the workers, the

\footnotetext{
${ }^{1}$ See Hummels et al. (2014) for a discussion on the flexibility of the Danish labor market.
} 
outside option for the supplier is greater than that of the final-good producer when he runs an integrated plant. Under plausible parameter configurations, the cutoff increases with capital intensity. Hence, worker bargaining power is more conducive to outsourcing in capital-intensive industries.

The theoretical results are robust to considering alternative contracting and bargaining assumptions: adopting a production function with an investment to produce the intermediate good, allowing for ex-ante lump-sum transfers in outsourcing contracts, and reversing the sequence of bargains. We also discuss how our theory can shed light on the relationship between firm scope and wages.

Our baseline theoretical model focuses on the integration decision of an individual producer. We derive theoretical results for intra-firm trade shares from a multi-country version of the model, using the framework developed in Antràs (2014a). From this exercise, we obtain empirical predictions linking firmlevel intra-firm import shares by country to empirical measures of worker bargaining power at the origin country-level, which are the subject of our empirical analysis.

One important assumption of our model is that of international rent-sharing within multinational firms. A group of empirical studies provide evidence supporting this hypothesis, by showing that wages paid by foreign affiliates are positively affected by the profits of their parent firms (e.g., Budd et al., 2005; Martins and Yang, forthcoming). ${ }^{2}$

Our work contributes to two important strands of the international trade literature. One is the work on collective bargaining and firms' internationalization strategies. Most of the existing work is theoretical and focuses on the incentives that unionization in domestic economies provides for firms to become horizontal multinationals (e.g., Zhao, 1995). A smaller group of papers studies the case of intermediate input sourcing. Skaksen and Sorensen (2001) neatly show that domestic unionization can generate incentives for firms to engage in vertical FDI. Skaksen (2004) finds that the threat of outsourcing to low-wage countries reduces homes wages, while realized outsourcing increases them (see also Lommerud et al., 2009). None of these works studies the vertical integration versus outsourcing decision. Furthermore, while the focus has been on workers in different countries producing for the same firm, we offer an explanation based on outsourcing used to reduce the share of revenues available for union extraction. Our model shares with Zhao (2001) the idea that the driver for vertical fragmentation is that the cost of bargaining breakdown is higher for the integrated firm. We extend this idea in different ways, and within a different setup. In our model, fragmentation arises when the bargaining power of workers is above a threshold. This generalization allows taking the theoretical implications to the data, where we use measures of worker bargaining power across countries (and industries in the case of imports from the US). The incomplete contract setting allows us to study the role of investment and to derive implications based on the capital intensity of the production technology.

Our results also contribute to a now well-developed scholarship on the theoretical and empirical determinants of intra-firm trade, built around the seminal work of Antràs (2003) and summarized in Antràs $(2014 \mathrm{a}, \mathrm{b})$. To the best of our knowledge, our paper is the first one to study role of worker bargaining power in shaping multinational firms' boundaries. We show empirically that labor market institutions are a strong determinant of intra-firm trade shares, with effects comparable to those of contracting and financial institutions. We also introduce the idea that labor market imperfections generate a source of

\footnotetext{
${ }^{2}$ Martins and Yang, forthcoming, use panel data for MNE-affiliate pairs in 47 countries. They find the effect to be increasing in the differences in per capita GDP across the locations of multinationals and their affiliates, consistently with rent-sharing occurring along vertical supply chains. Budd et al. (2005, p.1) mention the experience of the steel maker Corus that, in 2002, could face industrial action for freezing wages in the UK while increasing them in the Netherlands. The UK union stated "We all work for the same company, and we should all get the same deal."
} 
contractual incompleteness, additional to the contractual frictions between firms and their foreign suppliers that have been studied thus far. Our empirical evidence is consistent with the idea that, without the possibility of integrating their workers, firms tend to rely on external suppliers to alleviate this alternative hold-up problem. One contribution of our paper is to bridge the two strands of the literature mentioned in the preceeding paragraphs into one integrated analysis.

The rest of the paper is organized as follows. Section 2 develops the theoretical model and discusses the robustness analysis. Section 3 develops a multi-country model and presents the empirical predictions. Section 4 describes the estimating datasets and presents the empirical results. Section 5 concludes.

\section{A Simple Model}

We now develop a simple model of firm boundaries featuring labor market bargaining. We begin by studying firm behavior for a given demand. We describe the general equilibrium of the model in Section 3.1 below, where we analyze the implications for the share of intra-firm trade in a multi-country world.

\section{$2.1 \quad$ Set-up}

Three agents participate in production: a final-good producer $(\mathrm{F})$, a manufacturer of intermediate goods $(\mathrm{M})$, and a labor union $(\mathrm{U})$.

\section{Technology and Demand}

F owns the technology to produce a final good with demand $y=A p^{-1 /(1-\alpha)}$, where and $A$ is a shifter and $\alpha \in(0,1)$ governs the price elasticity. This demand schedule can be derived from consumer preferences that feature constant elasticity of substitution between differentiated varieties, as we do in Section 3.1.

Production requires the combination of two inputs: one investment in capital, $k$, and one intermediate good, $m$. Technology is represented by the following Cobb-Douglas production function:

$$
y(k, m)=\left(\frac{k}{\beta}\right)^{\beta}\left(\frac{m}{1-\beta}\right)^{(1-\beta)}
$$

For simplicity, we assume that one unit of labor is needed to produce one unit of the intermediate good: $m=l$. Revenues are:

$$
R(k, l)=A^{1-\alpha}\left(\frac{k}{\beta}\right)^{\beta \alpha}\left(\frac{l}{1-\beta}\right)^{(1-\beta) \alpha}
$$

\section{Organization of Production}

The final-good producer controls the provision of capital (which he rents at a fixed rate $r$ ). He decides on the organizational form under which production occurs from the following two alternatives:

1. Vertical Integration. $\mathrm{F}$ hires labor and employs $\mathrm{M}$ as the manager of the upstream division in charge of producing the intermediate good. F undertakes investments and combines capital with the intermediate good to produce and market the final good. 
2. Outsourcing. F outsources the production of the intermediate good to $\mathrm{M}$, who becomes an independent subcontractor. M hires labor, produces the intermediate good and trades it to $\mathrm{F}$, who undertakes investments and combines capital with the intermediate good to produce and market the final good.

The organizational decision dictates whether $\mathrm{M}$ is an internal employee or an unaffiliated subcontractor, and thus whether $\mathrm{F}$ keeps or not the production of the intermediate good within firm boundaries. Importantly, the decision determines who hires the necessary labor in the labor market. We assume that F chooses the organizational form that provides him with the highest payoff.

There are two types of contractual relationships. One type is that of labor contracts, which govern employment relationships of union members (and are signed either between $\mathrm{U}$ and $\mathrm{F}$ or between $\mathrm{U}$ and $\mathrm{M}$, depending on organizational choice). The other type is that of sourcing contracts, which govern the terms over which $\mathrm{F}$ and $\mathrm{M}$ trade the intermediate good. We now outline the contracting and bargaining assumptions that define employment and sourcing relationships. We start with the labor contract.

\section{The Employment Relationship: Contracting and Bargaining Assumptions}

A labor union $\mathrm{U}$ is composed of a continuum of workers L. Union members are homogenous in productivity and are each endowed with one unit of labor. $\mathrm{U}$ is the only supplier of labor available to F or M. Unemployed individuals obtain the reservation wage $\omega$.

Production of the intermediate good requires an agreement with $U$ that takes the form of a "labor contract." The labor contract specifies the individual wage and the level of employment. Wages and employment are bargained simultaneously following the efficient bargaining model of McDonald and Solow (1981) and using the generalized Nash Bargaining solution. Bargaining happens at the firm-level.

We assume that labor contracts are incomplete: no aspect of the employment relationship is assumed to be contractible ex-ante. Ex-ante agreements do not bind the union to providing the agreed quantity of labor at the agreed wage rate: at any time before production, it can call for renegotiation. The terms of the labor contract, which include both wages and the choice of labor, are determined through ex-post bargaining, once investments costs have been committed. Ex-post agreements are assumed to be binding. Importantly, the contractual environment governing the labor contract is identical whether the organizational choice is vertical integration or outsourcing. The difference is that under vertical integration $\mathrm{F}$ bargains with $\mathrm{U}$ whereas under outsourcing it is $\mathrm{M}$ that bargains with $\mathrm{U}$, which has consequences for determining the joint surplus that is bargained over.

The incompleteness of labor contracts and the hold-up problem associated with employment relationships are at the center of a large literature (see e.g., Cahuc et al., 2014). We do not model the reasons for such contract incompleteness. We take it as a relevant feature of the reality of industrial relations and study its implications for firm scope.

\section{The Sourcing Relationship: Contracting and Bargaining Assumptions}

Under outsourcing, $\mathrm{M}$ is the manager of an unaffiliated subcontracting firm. An outsourcing contract governs the terms of trade between $\mathrm{F}$ and $\mathrm{M}$. In keeping with the recent literature, we assume that outsourcing contracts are incomplete: no aspect is contractible ex-ante. We make the usual assumption that the relevant features of production (e.g., quality or customization) are perfectly observable for the 
parties in the relationship, but unverifiable by outside agents such as courts or mediators. The contractual environment we consider is close to what Antràs (2014a) labels "totally incomplete" contracts, with the difference being that he allows for ex-ante lump-sum transfers to be contracted upon. As with the case of labor contracts, we take contract incompleteness as a fact of the reality of outsourcing without modeling the reasons why binding contracts are unfeasible. The impossibility to write ex-ante enforceable contracts leads $\mathrm{F}$ and $\mathrm{M}$ to renegotiate the terms of trade through ex-post bargaining, after capital has been installed and the intermediate good has been produced. We model this ex-post bargaining with the generalized Nash Bargaining solution and assuming symmetric information at that stage. Ex-post agreements are assumed to be binding.

The case of vertical integration is assumed to be rather different. When $\mathrm{F}$ keeps the production of the intermediate good within firm boundaries, he enjoys full authority over M's actions. The consequence is that, at any time, $\mathrm{M}$ complies with all of the features that have been specified in an initial (ex-ante) contract, thus eliminating the need for ex-post renegotiation. Furthermore, F's power allows him to demand an ex-ante lump-sum transfer from $M$ that he uses to extract all the surplus accruing to the latter. Importantly, the effectiveness of F's authority in disciplining M under vertical integration holds irrespectively of the contracting environment governing outsourcing. These assumptions capture the spirit of the "transaction-cost" approach to firm boundaries (Coase, 1937; Williamson, 1985). ${ }^{3}$ They are, admittedly, strong assumptions, and they create an asymmetry with the outsourcing case. However, they allow us to succinctly capture the role of labor market bargaining in generating a trade-off between integration and outsourcing. As will become clear, our model highlights a cost of running vertically integrated firms that arises when labor is unionized. We refrain from imposing "governance costs" under integration (which is usual in transaction-cost models to generate a non-trivial trade-off between the cost of running firms and the cost of market transactions) since they would not alter the nature of any of the subsequent results.

\section{Specificity and Lock-in Effects}

We now describe the assumptions that determine the outside option for each party under each organizational form. We assume that both $k$ and $m$ are fully "relationship-specific." Both inputs need to be fully-tailored to the unique requirements of the variety produced by $\mathrm{F}$ and, once they have been produced, they are useless outside the relationship. We further assume that, when $\mathrm{F}$ bargains with M, it would be prohibitively costly for him to turn to alternative suppliers in case an agreement is not reached. For simplicity, we normalize to 0 the income that both agents might derive from other activities. These assumptions have important consequences. In an outsourcing partnership, once investment costs have been committed, F and M become "locked-in" with each other and the situation is one of bilateral monopoly. In light of the contract incompleteness plaguing the outsourcing relationship, a (double-sided) "hold-up" problem arises. In labor market bargaining, specificity implies that $\mathrm{F}$ has an outside option of 0 during the ex-post bargaining with U. Labor is homogenous, and all individuals are entitled to the reservation wage $\omega$ at any point in time. Workers do not undertake specific investments, and this asymmetry is a source of bargaining power for the union (the hold-up problem is one-sided).

For future record, we now recap the main contracting assumptions that define our baseline environment:

- A1: Labor contracts are incomplete: no aspect of the employment relationship is contractible ex-ante.

\footnotetext{
${ }^{3}$ Antràs (2014a) reviews the applications of this theory of the firm to settings similar to ours. A pedagogical example is provided in Antràs and Yeaple (2014).
} 
- A2: Outsourcing contracts are incomplete: no aspect of the commercial relationship between $\mathrm{F}$ and $\mathrm{M}$ is contractible ex-ante.

- A3: $k$ and $m$ are fully-specific to the particular variety produced by $\mathrm{F}$ and have 0 value for other producers. Furthermore, if the ex-post bargaining with M breaks down, F cannot turn to alternative suppliers of $m$.

In Section 2.3 we discuss the results obtained in more general environments.

\section{Timing}

The timing of events is the following. At the initial date $t=0, \mathrm{~F}$ chooses the organizational structure from the two alternatives introduced above. During the same period, he approaches $\mathrm{M}$ and proposes her an initial contract that specifies whether she becomes an employee or the manager of an independent subcontractor. The following period, $t=1$, is an investment stage where $\mathrm{F}$ invests in capital. Importantly, $k$ is sunk from this moment onwards. Next, at period $t=2$, wages and employment are bargained with the labor union $\mathrm{U}$. If vertical integration was chosen at $t=0$, the bargaining party is $\mathrm{F}$. Otherwise, if outsourcing was selected, $M$ bargains with $U$ as the head of the independent subcontracting firm. After an agreement with $\mathrm{U}$ is reached, the intermediate good is produced. This is followed by stage $t=3$, where $\mathrm{F}$ and $\mathrm{M}$ renegotiate their initial contract, engaging in a bargaining process over the terms of trade of the intermediate good. Given the above assumptions, such renegotiation takes place under outsourcing but not under vertical integration. Finally, at $t=4$, the terms of either the initial or the renegotiated contract are executed, depending on organizational form. Capital and the intermediate good are combined to produce the final good, which is then sold to final consumers.

We assume that all three agents have perfect information on all the parameters of the model, and that they perfectly forecast future payoffs associated with any actions taken.

\section{Benchmark: Efficient Production}

Before proceeding to the solution of the model, let us first define a benchmark of "productive efficiency," as a situation where factor demands are determined by the equality of each factor's marginal revenue product and its competitive price. The efficient pair $\left(k_{E}, l_{E}\right)$ is determined by the following conditions (the full expressions are provided in the Appendix):

$$
\frac{\partial R}{\partial k}=r \quad \frac{\partial R}{\partial l}=\omega
$$

Sales revenues evaluated at $\left(k_{E}, l_{E}\right)$ are:

$$
R_{E}=A \alpha^{\frac{\alpha}{1-\alpha}}\left(r^{\beta} \omega^{1-\beta}\right)^{\frac{-\alpha}{1-\alpha}}
$$

\subsection{Solution}

We now solve for the subgame perfect equilibrium of the model by using backward induction. We refer to expressions related to vertical integration and outsourcing using subscripts $v$ and $o$, respectively. 


\section{Vertical Integration}

At $t=4$, revenues $R\left(k_{v}, l_{v}\right)$ are generated. Given that M's actions are disciplined by F's authority, there is no renegotiation of the initial sourcing contract at $t=3$. Such an initial contract includes a lump-sum transfer from $\mathrm{M}$ to $\mathrm{F}$ that results in the latter getting all sales revenues. At $t=2, \mathrm{~F}$ and $\mathrm{U}$ bargain on wages and the level of employment. The incompleteness of labor contracts (A1) leads parties to bargain ex-post, after $\mathrm{F}$ has invested in capital. During the negotiations both agents have the capacity to stop production: in such an event, joint revenues are 0 . Consider the net gain each party gets from production (defined as the payoff from agreement net of the own outside option), starting with F. Capital has been sunk at $t=1$ and it is assumed to be fully-specific and to have no value for other producers (A3). If $\mathrm{U}$ refuses to provide labor, $\mathrm{F}$ is left with a capital stock that he cannot resell or combine with other labor. Hence, the outside option for $\mathrm{F}$ is 0 . In case production occurs, he obtains sales revenues net of labor costs, but gross of investment costs: $R\left(k_{v}, l_{v}\right)-w_{v} l_{v}$. Turning to U, every union member can obtain $\omega$ elsewhere: the outside option for the union is $\omega L$. We assume that the objective of $U$ is to maximize the "union rent," defined as the membership's aggregate income gains from employment, over and above the income that each member obtains in the event of no employment. U's net gain from production is $U\left(w_{v}, l_{v}\right)=\left(w_{v}-\omega\right) l_{v} \cdot{ }^{4}$

As mentioned in the previous subsection, we model labor market bargaining using the efficient bargaining model of McDonald and Solow (1981) and assuming it is represented by the generalized Nash Bargaining solution. We denote $\lambda$ the parameter representing the bargaining power of F. We think of $\lambda$ as determined by the laws and regulations affecting the relative power of firms and workers during collective negotiations.

The bargaining problem is written as:

$$
\max _{w_{v}, l_{v}} \Omega_{v}=\left[R\left(k_{v}, l_{v}\right)-w_{v} l_{v}\right]^{\lambda}\left[\left(w_{v}-\omega\right) l_{v}\right]^{1-\lambda}
$$

Subject to $0 \leq l \leq L$ and $w \geq \omega$. The first-order conditions (FOCs) can be rearranged to give:

$$
w_{v}=(1-\lambda) \frac{R\left(k_{v}, l_{v}\right)}{l_{v}}+\lambda \omega \quad \frac{\partial R}{\partial l}=\omega
$$

The first expression shows that bargained wages $w_{v}$ are a weighted sum of revenues per worker and the reservation wage, with weights equal to the bargaining power of workers and the final-good producer, respectively. The higher $\lambda$, the smaller the extent of rent-sharing. The second expression shows that employment is determined by the equality of the marginal revenue product of labor and $\omega$ : for a given value of the capital stock $k_{v}$, labor is used efficiently irrespectively of $\lambda$. With all bargaining power on F's side $(\lambda=1)$ we have $w=\omega$. Generally, with $0<\lambda<1$ the solution entails $w>\omega$ which implies that the union obtains positive rents. ${ }^{5}$

At the investment stage $t=1, \mathrm{~F}$ chooses the level of capital to maximize his payoff $\pi_{v}=R\left(k_{v}, l_{v}\right)-$ $w_{v} l_{v}-r k_{v}$, anticipating the outcome of the negotiations with U. Using the expressions derived above the

\footnotetext{
${ }^{4}$ This formulation of the objective function is consistent with the union being utilitarian and composed of risk-neutral workers (thus seeking to maximize the sum of the individual members' income, see Cahuc et al., 2014). It can also be obtained with the Stone-Geary utility function and assuming the union values wages and employment equally.

${ }^{5}$ The result that labor is chosen efficiently follows from the assumption of a rent-maximizing union. The solution presented here is labeled "strongly efficient" in the literature because it entails both "productive efficiency" (conditional on the level of capital) and "Pareto efficiency"(Cahuc et al., 2014).
} 
problem is written as:

$$
\max _{k_{v}} \pi_{v}=\lambda R\left(k_{v}, l_{v}\right)-\lambda l_{v} \omega-r k_{v}
$$

With FOC: $\frac{\partial R}{\partial k}=\frac{r}{\lambda}$. Thus, $\lambda$ influences the choice of $k_{v}$ : it is a consequence of the combined effect of assumptions A1 and A3, and the associated hold-up problem. ( $\lambda$ affects the equilibrium value of $l_{v}$ indirectly through its effect on $k_{v}$.)

The expressions in (6) and the FOC of (7) form a system of equations, the solution of which gives equilibrium values for $\left(k_{v}, l_{v}, w_{v}\right)$ (see the Appendix). Replacing into (2) and (7) we obtain equilibrium revenues and profits under vertical integration:

$$
R_{v}=A \alpha^{\frac{\alpha}{1-\alpha}}\left(\left(\frac{r}{\lambda}\right)^{\beta} \omega^{1-\beta}\right)^{\frac{-\alpha}{1-\alpha}} \quad \pi_{v}=\lambda(1-\alpha) A \alpha^{\frac{\alpha}{1-\alpha}}\left(\left(\frac{r}{\lambda}\right)^{\beta} \omega^{1-\beta}\right)^{\frac{-\alpha}{1-\alpha}}
$$

The parameter $\lambda$ appears twice in $\pi_{v}$, highlighting two effects of wage bargaining on profits. One is a pure rent-sharing effect: the bargaining process leaves $\mathrm{F}$ with a share $\lambda$ of the ex-post gains from production. The second is an efficiency effect: the incompleteness of the labor contract coupled with the full-specificity of capital leads to a hold-up problem that distorts ex-ante incentives to invest, reducing total revenues. The lower $\lambda$, the stronger the distortion. The choices of $\left(k_{v}, l_{v}\right)$ and the resulting $R_{v}$ are identical to those that would be obtained in a frictionless setting with a rental rate of capital of $\frac{r}{\lambda}$, as a comparison of the FOC of (7) with (3) reveals. In his seminal contribution, Grout (1984) called $\frac{1}{\lambda}$ the "implicit cost of capital." Naturally, the lower $\lambda$, the higher this implicit cost is and the lower the level of $k_{v}$. In comparison with those that would be obtained in a frictionless environment as defined by (4), revenues are reduced by a factor $\lambda^{\frac{\beta \alpha}{1-\alpha}}<1 .^{6}$

The following Lemma establishes formally how $\pi_{v}$ is affected by changes in $\lambda$ :

Lemma 1 F's payoff under vertical integration, $\pi_{v}$, satisfies $\frac{\partial \pi_{v}}{\partial \lambda}>0$.

Proof. See the Appendix.

F's payoff is increasing in his bargaining power: higher $\lambda$ leads $\mathrm{F}$ to reap a larger share of surplus and boosts investment, leading to more efficient production and higher total revenues.

\section{Outsourcing}

We now turn to outsourcing. At $t=3$, once $k_{o}$ and $m_{o}$ have been invested and are ready to be combined to generate sales revenues $R\left(k_{o}, m_{o}\right)$ at $t=4, \mathrm{~F}$ and $\mathrm{M}$ sit down to renegotiate a price for the intermediate good. We model the negotiations using a generalized Nash Bargaining process, the outcome of which leaves each party with the value of its outside option plus a share of the ex-post gains from trade. We assume that $\mathrm{F}$ obtains a share $\phi$ and $\mathrm{M}$ a share $(1-\phi)$ of the ex-post gains from trade. Consider the outside options available to the parties, bearing in mind the assumption of full-specificity of $k$ and $m$ (A3). At the time bargaining takes place, $\mathrm{M}$ has already produced the intermediate good (paying the cost $w_{o} l_{o}$ to remunerate the labor union). In case an agreement with $\mathrm{F}$ is not reached, she will be left with a component that she cannot resale to other producers, and thus with a payoff of 0. Similarly, F has invested in $k_{o}$. He

\footnotetext{
${ }^{6}$ In fact, our model under vertical integration is a special case of the Grout (1984) model, which is based on generic profit functions and that did not consider the possibility to outsource. Grout assumed capital had a positive resale value but lower than its purchase price. By assuming fully-specific capital, we are setting the resale value of $k$ to zero.
} 
does not have time to turn to other potential suppliers or obtain any income from selling the capital stock to other final-good producers. Hence, both parties have an outside option of 0 . Under these assumptions, the bargaining process leaves $\mathrm{F}$ with a payoff of $\phi R\left(k_{o}, m_{o}\right)$ and $\mathrm{M}$ with a payoff of $(1-\phi) R\left(k_{o}, m_{o}\right)$.

At $t=2, \mathrm{M}$ engages in negotiations with $\mathrm{U}$ to secure the labor required for the production of the intermediate good. The assumptions framing the bargaining process are exactly the same as those of the case of vertical integration. The only difference is that now it is $\mathrm{M}$ who bargains with $\mathrm{U}$, following the assumption of the firm-level labor market bargaining. Hence, finding the bargaining outcome requires solving a problem similar to (5) but adjusting the payoffs accordingly. ${ }^{7}$ What M stands to gain from production is the income derived from selling the intermediate good to $\mathrm{F}$, net of labor costs: $(1-\phi) R\left(k_{o}, l_{o}\right)-w_{o} l_{o}$. In the event of a negotiation breakdown, $\mathrm{M}$ is unable to produce the intermediate good and keeps his outside income that has been normalized to 0 . The union's objective is to maximize the union rent: $U\left(w_{o}, l_{o}\right)=\left(w_{o}-\omega\right) l_{o}$. FOCs are:

$$
w_{o}=(1-\lambda)(1-\phi) \frac{R\left(k_{o}, l_{o}\right)}{l_{o}}+\lambda \omega \quad \frac{\partial R}{\partial l}=\frac{\omega}{(1-\phi)}
$$

At the investment stage $t=1, \mathrm{~F}$ chooses the level of capital to maximize his payoff $\pi_{v}=R\left(k_{o}, l_{o}\right)-$ $w_{o} l_{o}-r k_{o}$. The problem is written as:

$$
\max _{k_{o}} \pi_{o}=\phi R\left(k_{o}, l_{o}\right)-r k_{o}
$$

with FOC $\frac{\partial R}{\partial k}=\frac{r}{\phi}$. Two main differences with the vertical integration case stand out. First, wages are a weighted sum of the reservation wage and the suppliers' per-worker revenues. Second, ex-ante incentives to invest are different. Factor demands are determined by the share of ex-post gains obtained by $\mathrm{F}$ and $\mathrm{M}$ in the negotiation occurring at $t=3$.

Using $\frac{\partial R}{\partial k}=\frac{r}{\phi}$ together with (9) we can solve for the equilibrium values of $\left(k_{o}, l_{o}, w_{o}\right)$ (provided in the Appendix). We obtain total revenues and F's equilibrium payoff under outsourcing $\pi_{o}$ :

$$
R_{o}=A \alpha^{\frac{\alpha}{1-\alpha}}\left(\left(\frac{r}{\phi}\right)^{\beta}\left(\frac{\omega}{1-\phi}\right)^{1-\beta}\right)^{\frac{-\alpha}{1-\alpha}} \quad \pi_{o}=\phi(1-\beta \alpha) A \alpha^{\frac{\alpha}{1-\alpha}}\left(\left(\frac{r}{\phi}\right)^{\beta}\left(\frac{\omega}{1-\phi}\right)^{1-\beta}\right)^{\frac{-\alpha}{1-\alpha}}
$$

Inefficiencies arise from the hold-up problem affecting the outsourcing relationship, as it is apparent from the revenue function $R_{o}$ in (11). The effect of contract incompleteness is analogous to an increase in factor costs, of $\frac{1}{\phi}$ and $\frac{1}{1-\phi}$ for $k$ and $l$, respectively. Compared to those that would be obtained in a frictionless environment as defined by (4), revenues are reduced by a factor $\left[\phi^{\beta}(1-\phi)^{1-\beta}\right]^{\frac{\alpha}{1-\alpha}}<1$. Given that $\mathrm{M}$ does not undertake any ex-ante investments in specific capital, and that labor is chosen efficiently, the incompleteness of labor contracts has no bearing in optimal investments and revenues. $\lambda$ plays a pure redistributive role between $\mathrm{M}$ and $\mathrm{U}$. M's payoff is:

\footnotetext{
${ }^{7} \lambda$ is thought to be determined by the institutions determining the division of rents between firms and workers. One could adapt the model to understand $\lambda$ as the equilibrium share obtained by firms when negotiating with workers. It could be justified on the grounds that some firms can shift production across plants, having an outside option. This feature has been extensively studied (e.g., Zhao, 1995), and we prefer to abstract from it and focus on the novel implications of our model.
} 


$$
\pi_{o}^{M}=\lambda(1-\phi)(1-(1-\beta) \alpha) A \alpha^{\frac{\alpha}{1-\alpha}}\left(\left(\frac{r}{\phi}\right)^{\beta}\left(\frac{\omega}{1-\phi}\right)^{1-\beta}\right)^{\frac{-\alpha}{1-\alpha}}
$$

Inspection of (11) shows that $\pi_{o}$ is unaffected by $\lambda .^{8}$

\section{Worker Bargaining Power and Firm Boundaries}

Roll now the clock back to $t=0$. At this point in time, $\mathrm{F}$ makes organizational choices by comparing the payoffs which he perfectly anticipates that each strategy provides. Vertical integration will be chosen whenever $\Gamma \equiv \frac{\pi_{v}}{\pi_{o}}>1$. Using (8) and (11):

$$
\Gamma(\lambda, \beta, \phi, \alpha)=\frac{\lambda^{\frac{1-(1-\beta) \alpha}{1-\alpha}}(1-\alpha)}{\phi(1-\beta \alpha)\left(\phi^{\beta}(1-\phi)^{1-\beta}\right)^{\frac{\alpha}{1-\alpha}}}
$$

Expression (13) depends on all the parameters of the model, but we are particularly interested in how the bargaining power of workers in industrial relations shapes the optimal boundaries of the firm. Solving for the value of $\lambda$ for which $\Gamma>1$, we find:

$$
\lambda^{*}(\beta, \phi, \alpha) \equiv\left[\frac{\phi(1-\beta \alpha)\left(\phi^{\beta}(1-\phi)^{1-\beta}\right)^{\frac{\alpha}{1-\alpha}}}{(1-\alpha)}\right]^{\frac{1-\alpha}{1-(1-\beta) \alpha}}
$$

The following Proposition establishes formally how F's organizational choices depend on $\lambda$ :

Proposition 1 There exists a unique cutoff $\lambda^{*}(\beta, \phi, \alpha) \in(0,1)$ such that: for $\lambda>\lambda^{*}(\beta, \phi, \alpha)$ the finalgood producer chooses to setup a vertically integrated plant, for $\lambda<\lambda^{*}(\beta, \phi, \alpha)$ he chooses to outsource the intermediate good, and for $\lambda=\lambda^{*}(\beta, \phi, \alpha)$ he is indifferent between the two organizational forms.

Proof. See the Appendix.

Proposition 1 provides the main result of the theoretical analysis: empowering workers increases the profitability of outsourcing over vertical integration. When $\lambda$ is high, the optimal organizational form is that of vertical integration. Decreases in $\lambda$ imply that $\mathrm{F}$ gives away a larger share of ex-post revenues to $\mathrm{U}$ which, given our contracting and bargaining assumptions, also distorts his ex-ante incentives to invest, and further reduces $\pi_{v}$ (see Lemma 1). By subcontracting, the final-good producer avoids the bargain with $\mathrm{U}$, with the result that $\pi_{o}$ is independent of $\lambda$. For values of $\lambda$ sufficiently low, outsourcing becomes the preferred organizational form. ${ }^{9}$

A comparative static analysis on the cutoff $\lambda^{*}(\beta, \phi, \alpha)$ leads to the following result:

Proposition 2 The cutoff $\lambda^{*}(\beta, \phi, \alpha)$ is increasing in $\beta$ for $\phi>1-e^{-b(\beta, \alpha)}$, decreasing in $\beta$ for $\phi<$ $1-e^{-b(\beta, \alpha)}$, and independent of $\beta$ for $\phi=1-e^{-b(\beta, \alpha)}$, with $b(\alpha, \beta)=(1-\alpha)\left[\frac{1-\alpha+\beta \alpha}{1-\beta \alpha}+\ln \left(\frac{1-\beta \alpha}{1-\alpha}\right)\right]$ Proof. See the Appendix.

\footnotetext{
${ }^{8}$ In the robustness analysis of Section 2.3 we discuss two extensions in which $\pi_{o}$ becomes a function of $\lambda$ : considering a production function with a specific investment by $\mathrm{M}$, and allowing for ex-ante transfers between $\mathrm{F}$ and $\mathrm{M}$ under outsourcing. The results of the baseline model carry through. (The full details are provided in the Online Appendix.).

${ }^{9}$ One important feature of the solution is that $\lambda^{*}(\beta, \phi, \alpha)$ does not depend on $(\omega, r)$. Given the Cobb-Douglas production function and the demand system we consider, factor prices do not impact the ratio $\pi_{v} / \pi_{o}$.
} 
The impact of worker bargaining power on the organizational choice depends on the capital intensity of the production technology. Proposition 2 provides the second important result arising from the model. It states that, under certain parameter configurations that we will argue below are plausible, outsourcing is more likely when the technology is capital-intensive and the power of firms in the bargaining with workers is weak: the higher $\beta$, the higher $\lambda^{*}(\beta, \phi, \alpha)$, and thus the larger the range of $\lambda$ for which $\pi_{v}<\pi_{o}$.

The intuition behind the results of Proposition 2 is the following. As capital becomes more important, underinvestment in $k$ becomes more value-reducing, and F's payoff under vertical integration is lower for all values of $\lambda$. Under outsourcing, revenues are increasing in capital intensity when the share obtained by $\mathrm{F}$ in the ex-post bargaining is large, because $\mathrm{F}$ is the party in charge of the capital investments. Therefore, for large enough values of $\phi$, increases in capital intensity reduce the ratio $\pi_{v} / \pi_{o}$ for all $\lambda$, leading to a higher $\lambda^{*}(\beta, \phi, \alpha){ }^{10}$

Figure 1 plots the contours implicitly defined by $\phi=1-e^{-b(\beta, \alpha)}$ in the $(\alpha, \beta)$ space, using different values for $\phi$. Points above each line give those pairs $(\alpha, \beta)$ for which $\phi>1-e^{-b(\beta, \alpha)}$.

Figure 1: The effect of capital intensity under different parameter configurations

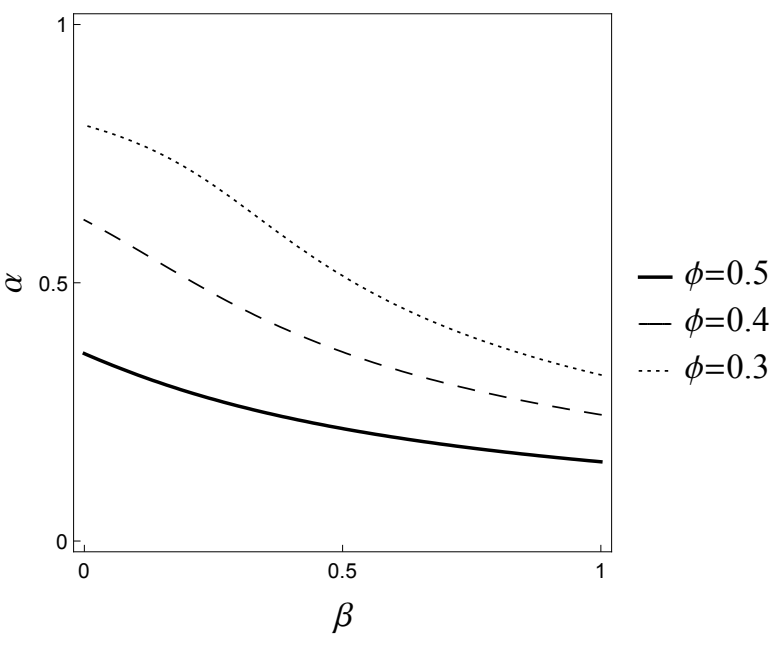

The main message of Figure 1 is that the condition $\phi>1-e^{-b(\beta, \alpha)}$ is likely to hold under plausible parameter values. To see this point, note that $\alpha$ is likely to be in the range $(0.5,1)$. Those are realistic values if $\alpha=1-1 / \sigma$, where $\sigma$ is the elasticity of substitution between differentiated varieties (see Section 2.4 below). The median estimate of $\sigma$ in Broda and Weinstein (2006) is close to 4. Similarly, it is reasonable to consider cases with $\beta<0.5 .{ }^{11}$ For those parameter ranges the condition is always met for $\phi=0.5$, and it is quite likely to hold for lower values of $\phi$. Empirical estimates of $\phi$ are scarce. Feenstra and Hanson (2005) report a value of $\phi=0.5$, estimated using data on foreign firms operating in China (their estimate is of $\phi=0.7$, but not statistically different from 0.5 at conventional levels).

This completes the analysis of the baseline model. Let us remark here that the results of Proposition 2 hinge on the assumption that capital investment is relationship-specific and has no outside value (A3), which leads to a hold-up problem because contracts are incomplete (A1 and A2). Without this hold-up

\footnotetext{
${ }^{10}$ In the Online Appendix we study how $\pi_{v}$ and $\pi_{o}$ are affected by $\beta$.

${ }^{11}$ For example, Fally (2012) uses US input-output tables from the BEA and finds that the total share of intermediate goods in US production is around 0.5, implying a value of $\beta$ below 0.5 .
} 
problem, the effect of $\lambda$ on organizational choices is independent of $\beta$. In the empirical analysis we account for relationship-specificity when we study the effect of capital intensity on organizational choices.

\subsection{Extensions and robustness analysis}

In this section we discuss the robustness of the results to a set of alternative technological, contracting, and bargaining assumptions. The details of the derivations are provided in the Online Appendix.

\section{Introducing a specific investment to produce the intermediate good}

Imagine that production of the intermediate good requires $\mathrm{M}$ to undertake an investment in relationshipspecific capital $k_{m}$, according to the following technology: $m\left(k_{m}, l\right)=\left(\frac{k_{m}}{\xi}\right)^{\xi}\left(\frac{l}{1-\xi}\right)^{1-\xi}$ with $0<\xi<1$. Call $k_{f}$ the investment by $\mathrm{F}$. In this setting, and as before, outsourcing allows for avoiding the deterring effects of labor contract incompleteness on the choice of $k_{f}$. However, $k_{m}$ is subject to labor opportunism to the same extent under both organizations. Revenues are reduced by the same proportion by the underinvestment in $k_{m}$. Hence, the ratio $\frac{\pi_{v}}{\pi_{o}}$ is the same as in (13) and thus Propositions 1 and 2 hold.

\section{Allowing for ex-ante transfers in outsourcing contracts}

Assume the outsourcing contract allows for enforceable ex-ante lump-sum transfers between F and M, as in Antràs (2003) and related works. No other aspect of the outsourcing relationship is ex-ante contractible. The transfer occurs at $t=0$, before the investment and bargaining stages. The structure of the game in periods $t=1$ to $t=4$ is identical to that of the baseline model.

We focus on the case with an unbounded pool of potential agents $M$ that are willing to supply the intermediate good and obtain an income equal to their outside opportunity (which has been normalized to zero). F picks one of such agents and makes her a take-it-or-leave-it offer, in which the transfer is set to extract the entire ex-post surplus (i.e. making the participation constraint of the supplier bind). The transfer is non-distortionary, hence all subsequent actions are unchanged.

F's payoff under vertical integration is given as before by $\pi_{v}$ in (8). Ex-post payoffs for $\mathrm{F}$ and $\mathrm{M}$ under outsourcing are given in (11) and (12), respectively, and thus F's expected payoff from outsourcing is $\pi_{o}^{T}=\pi_{o}+\pi_{o}^{M}$. Importantly, $\pi_{o}^{T}$ is an increasing function of $\lambda$, because $\lambda$ affects the surplus obtained by the supplier in labor market bargaining (see the expression for $\pi_{o}^{M}$ ). Under this alternative contracting setting, F chooses the organizational form that maximizes total corporate profits, net of labor costs (instead of his own ex-post payoff). The two main results of Section 2.2 carry on: there is a unique value $\lambda^{*}(\beta, \phi, \alpha)$ determining organizational choices, and this value is increasing in $\beta$ for large enough values of $\phi$.

\section{Input price bargained before wages under outsourcing}

We now discuss the case of an inverse sequence of bargains under outsourcing. At the beginning of period $t=2, \mathrm{~F}$ and $\mathrm{M}$ bargain over a payment $\mathrm{P}$ to which $\mathrm{M}$ is entitled if she produces the intermediate good and trades it to F. Such bargaining happens right before M bargains with $U$ (and thus before production of the intermediate good), but after $\mathrm{F}$ has invested in $k$. Importantly, there is no renegotiation of $\mathrm{P}$ at a later stage. ${ }^{12}$ For comparability with our baseline environment we model this negotiation with a generalized

\footnotetext{
${ }^{12}$ This can result if the payment $\mathrm{P}$ occurs at the same period in which $\mathrm{M}$ hands the intermediate good to $\mathrm{F}$. Note that enforcing $\mathrm{P}$ would require information on sales revenues and employment, but not on specific investments.
} 
Nash bargaining process where F's bargaining power is $\phi$ and M's is $(1-\phi)$. In the bargain over P both agents anticipate the outcome of the future negotiation with $U$, which implies that M's net gains from trade with $\mathrm{F}$ equal $P-w_{o} l_{o}$.

There are two important changes. One is that the possibility of committing on $\mathrm{P}$ before production of $m$ naturally eliminates the hold-up problem affecting the choice of labor. The other one is that the bargaining problem between $\mathrm{F}$ and $\mathrm{M}$ internalizes the cost of ensuring the workers' participation in production. Compared to the baseline model, F's ex-ante payoff is lower and M's is higher (for given levels of investments). Other than this, $\lambda$ continues to play a redistributive role affecting the division of surplus between $\mathrm{M}$ and $\mathrm{U}$.

These changes notwithstanding, there exists a unique cutoff $\lambda^{*}(\beta, \phi, \alpha) \in(0,1)$ determining the organizational choice, and it behaves qualitatively with respect to $\beta$ in the same manner as in the baseline model.

\section{Firm scope and wages}

Outsourcing has often been cited as a strategy aimed at reducing wages in unionized firms. A simple extension of our framework can shed light on the impact of fragmentation on individual wages. The functional forms for technology and demand that we use imply that employment adjusts to organizational changes in a way such that individual wages remain the same: $w_{v}=w_{o}$ irrespective of $\lambda$ (see the paper's Appendix for the detailed expressions). The insensitivity of wages to changes in a revenue shifter under these functional forms is well-known in the labor economics literature (e.g., McDonald and Solow, 1981).

A mild modification of our model generates individual wages that vary with organizational choices. Assume that production of $m$ requires a fixed cost in terms of non-relationship-specific capital $f$. It can be thought of as non-specialized equipment that can be setup right before production and has a resale value equal to its cost. Given non-specificity, the costs of $f$ are shared between the labor union and the corresponding bargaining agent ( $\mathrm{F}$ or $\mathrm{M})$.

Importantly, under this new configuration, the revenues-to-employment ratio increases with revenues. Outsourcing reduces the revenues that are bargained over with $\mathrm{U}$, therefore reducing individual wages as well. Thus, our model puts forward an "organizational channel," to explain the relationship between fragmentation and wages. As in the baseline model, there is a unique cutoff $\lambda^{*}(\beta, \phi, \alpha) \in(0,1)$ determining the organizational choice, and it increases with $\beta$ for values of $\phi$ above a certain threshold. An interesting result that arises in this modified setting is that, in the neighborhood of $\lambda^{*}$, increasing union power (decreasing $\lambda$ ) leads to a decrease in wages. We close by noting that, in the baseline model, similar conclusions can be derived for union welfare.

\section{Multi-Country Model and Empirical Implementation}

In this section we derive the empirical implications of the model in terms of intra-firm trade shares at the bilateral country-level, both for individual producers and at the aggregate level. The section provides the transition for the empirical analysis carried out in Section 4 below, that relies on firm-level data on intra-firm import shares by multinationals located in France. 


\subsection{Multi-country model}

We now embed the model into a simple version of the multi-country global sourcing model developed in Antràs (2014a) (based on Antràs et al., 2014, and Tintelnot, 2014). Consider a world composed of $J$ countries and two sectors. One sector produces a homogeneous good $y$ under constant returns to scale, and the other one produces a continuum of slightly differentiated varieties of a generic good $Q$. Consumers have the same preferences all over the world. They spend a share $\gamma$ of their income in the consumption of $Q$, having Dixit-Stiglitz preferences over the continuum of varieties. Demand for variety $x$ is $q(x)=\gamma E P^{\frac{\alpha}{1-\alpha}} p(x)^{\frac{-1}{1-\alpha}}$, where $P$ is the ideal price index associated with $Q, E$ is world income, and $\alpha=1-1 / \sigma$ where $\sigma>1$ is the constant elasticity of substitution between any two varieties. There is free trade in final goods in both sectors.

Regarding the supply side, we assume for simplicity that there is a unique composite factor of production, labor, which is supplied inelastically and freely mobile across sectors. Each country $j$ is endowed with $L_{j}$ units of labor. The homogeneous good is assumed to be produced in all countries and in large quantities (due to low $\gamma$ ) so that the reservation wage $\omega_{j}$ is determined by labor productivity in that sector (thus differences in labor productivity across countries generate differences in $\omega_{j}$ ). The good $y$ serves as the numeraire. These assumptions are standard in the theory of multinational firm boundaries (e.g., Antràs and Helpman, 2004) and allow us to treat factor prices as given. ${ }^{13}$

The market structure in the differentiated sector is that of monopolistic competition. In every country $i \in J$ there is a measure $N_{i}$ of final-good producers $\left(F_{i}\right)$ who own the prototype for developing a unique variety $x$. Production requires combining capital $k$ with one intermediate good $m$. Technology is given by (1) but includes a $F_{i}$-specific "core productivity" parameter $\varphi$, which is Hicks-neutral (as in the Melitz model). Each $F_{i}$ is indexed by a unique value of $\varphi$, and the distribution of the $\varphi^{\prime} s$ is identical in all countries. ${ }^{14}$ The intermediate good can be sourced from any one of the $J$ countries, and its production can occur under vertical integration or outsourcing. Firm performance depends on two extra parameters. $a_{h i}$ are the unit factor requirements to invest in $k$ (or generally to customize it to be specific to variety $x$ ). It is common to all firms located in country $i . a_{m j z}$ is firm-specific and indexes the unit labor requirements associated with the production of intermediate goods in country $j$ under organization $z$, where $z \in\{V, O\}$ is an indicator variable for vertical integration $(\mathrm{V})$ or outsourcing $(\mathrm{O}) . a_{m j z}$ can be referred to as an inverse measure of "sourcing productivity." Importantly, sourcing productivity parameters are realizations of a random variable (we provide details below). Shipping intermediate goods from $j$ to $i$ entails trade costs of the iceberg-type equal to $\tau_{i j}$.

Using the demand function for $x$, together with the production technology, we can express the sales revenues a firm headquartered in $i$ obtains if sourcing $m$ from country $j$ under organizational form $z$ :

$$
R_{i j z}(\varphi)=A^{1-\alpha} \varphi^{\alpha}\left(\frac{k}{a_{h i} \beta}\right)^{\beta \alpha}\left(\frac{m}{a_{m j z} \tau_{i j}(1-\beta)}\right)^{(1-\beta) \alpha}
$$

with $A=\gamma E P^{\frac{\alpha}{1-\alpha}}$. The profitability associated with sourcing $m$ is specific to firms, source-countries and organizational forms.

\footnotetext{
${ }^{13}$ Departing from this standard framework (for example by considering more than one production factor) would complicate the analysis, leading us out of the scope of this section. Furthermore, the share of intra-firm trade at the country-level will prove to be independent of factor prices, for similar reasons making the cutoff (14) in Section 2.2 independent of factor prices.

${ }^{14}$ We would obtain similar predictions in terms of intra-firm trade shares should we consider that entry is subject to fixed costs and determined by a free-entry condition.
} 
The differentiated sector is unionized in all $j \in J$ and labor market bargaining happens at the firm level. Each firm attempting to produce in $j$ bargains with a single labor union, with the bargaining power of firms being governed by the parameter $\lambda_{j}$. Consider the case of a final-good producer $F_{i}$ with headquarters in $i$ that decides to source from $j$. If $F_{i}$ chooses vertical integration, he hires a local agent $M_{j}$ as the manager of the unit in $j$ in charge of producing the intermediate good. $F_{i}$ 's firm thus becomes a multinational firm headquartered in $i$, and needs to agree with a labor union $U_{j}$ to produce. Alternatively, he can propose the local agent $M_{j}$ an (international) outsourcing contract, in which case $M_{j}$ is in charge of bargaining with $U_{j}$ as the head of an independent firm located in $j . F_{i}$ and $M_{j}$ bargain ex-post over the terms of exchange and their bargaining powers are given respectively by $\phi_{j}$ and $\left(1-\phi_{j}\right){ }^{15}$ Interactions between $F_{i}, M_{j}$ and $U_{j}$ in each source country $j$ take place after the realization of $a_{m j z}$, which is taken as given by the three agents during the contracting and bargaining stages. Contracts are incomplete and $k$ and $m$ are fully relationship-specific. Using the revenue function (15), it is easy to follow the steps of Section 2.2 to obtain operating profits for a final-good producer with headquarters in country $i$, sourcing from country $j$ under organizational form $z$ :

$$
\pi_{i j z}(\varphi)=A \alpha^{\frac{\alpha}{1-\alpha}}\left(\left(\omega_{i} a_{h i}\right)^{\beta}\left(\omega_{j} a_{m j z} \tau_{i j}\right)^{1-\beta}\right)^{\frac{-\alpha}{1-\alpha}} \varphi^{\frac{\alpha}{1-\alpha}} \Upsilon_{i j z}
$$

$\Upsilon_{i j z}$ summarizes the contractual frictions. It depends on the bargaining $\left(\lambda_{j}, \phi_{j}\right)$, technological $(\beta)$, and demand parameters $(\alpha)$ of the model (contrary to $a_{m j z}, \Upsilon_{i j z}$ is not firm-specific). $\Upsilon_{i j z}=1$ implies no contractual distortion, but generally we have $\Upsilon_{i j z}<1$.

There are fixed costs $f_{i j z}$ to obtain a draw $a_{m j z}$. We follow Antràs (2014a) and make the simplifying assumption that $f_{i j V}$ and $f_{i j O}$ are small enough so that all final-good producers from every country $i$ find it optimal to incur them for every country $j$ and organizational form $z .{ }^{16}$ While final-good producers get draws for all countries, they only source from a single market in equilibrium because they only need one intermediate good. The stochastic sourcing productivity parameter $1 / a_{m j z}$ is drawn from a Fréchet distribution:

$$
\operatorname{Pr}\left(a_{m j z} \geq a\right)=e^{-T_{j} a^{\theta}}
$$

With $T_{j}>0$ and $\theta>\frac{\alpha(1-\beta)}{1-\alpha} . T_{j}$ and $\theta$ have the same interpretation than in Eaton and Kortum (2002). $T_{j}$ governs the location of the distribution (bigger values make high efficiency draws more likely). $\theta$ reflects the variation within the distribution (lower values imply greater variability). We consider the simplest case where these draws are independent across firms, locations, and organizational forms. Final-good producers pick the $j$ and $z$ that maximize operating profits (16), which is equivalent to minimizing the following expression: $\omega_{j} a_{m j z} \tau_{i j} \Upsilon_{i j z}^{-\frac{1-\alpha}{(1-\beta) \alpha}}$. Some $F_{i}$ might decide to source from countries where workers have high bargaining power (low $\lambda_{j}$, leading to low $\Upsilon_{i j z}$ ) if their sourcing productivity there is high - or the other costs $\left(\omega_{j}, \tau_{i j}\right)$ are low. Based on the properties of the Fréchet, we can calculate the probability that final-good producers in $i$ will source intermediate goods from $j$ under organizational form $z$ :

\footnotetext{
${ }^{15}$ For symmetry we assume that the ex-post share obtained by $F_{i}$ under outsourcing is a country-specific variable, like $\lambda_{j}$. It could be argued that $\phi$ is firm- or sector-specific. In the empirical analysis we take an agnostic view and discuss how we deal with the different possibilities.

${ }^{16}$ In a more general model the fixed costs would vary across countries and organizational forms. Antràs et al. (2014) present a model where productivity determines the set of countries where firms source from, but does not consider the internalization decision. A theory of sorting into organizational forms according to productivity is provided in Antràs and Helpman (2004), and evidence in Corcos et al. (2013) and Defever and Toubal (2013).
} 


$$
\chi_{i j z}=\frac{T_{j}\left(\omega_{j} \tau_{i j} \Upsilon_{i j z}^{-\frac{1-\alpha}{(1-\beta) \alpha}}\right)^{-\theta}}{\sum_{l \in J} \sum_{z^{\prime} \in\{V, O\}} T_{l}\left(\omega_{l} \tau_{i l} \Upsilon_{i l z^{\prime}}^{-\frac{1-\alpha}{(1-\beta) \alpha}}\right)^{-\theta}}
$$

Given that there is a continuum of final-good producers in each country, by the law of large numbers, (17) is also the share of intermediate goods that firms in $i$ import from $j$ under organization form $z$.

The literature typically considers the share of intra-firm trade, defined as the ratio of the value of intermediate goods imported within multinational firm boundaries to the total value of imports. Deriving predictions in terms of this share requires us to take a stand on how intermediate goods are priced. We follow Antràs (2014a) and make the convenient assumption that prices are such that intermediate goods account for the same multiple of operating profits irrespective of location and organization. ${ }^{17}$ In that case the share of intra-firm trade in total imports is an (inverse) function of the contractual distortion of vertical integration relative to that of outsourcing. For any importer country $i$ and any exporter country $j$ :

$$
S h_{-} i n t r a_{i j}=\frac{\Gamma_{i j}^{\frac{(1-\alpha) \theta}{(1-\beta) \alpha}}}{1+\Gamma_{i j}^{\frac{(1-\alpha) \theta}{(1-\beta) \alpha}}}
$$

where $\Gamma_{i j}=\frac{\Upsilon_{i j V}}{\Upsilon_{i j O}}$, is the counterpart to (13). The intuitions governing the organizational choice of an individual final-good producer smoothly carry on to the aggregate share. There exists a cutoff value $\lambda_{j}^{*}$ such that $\Gamma_{i j}\left(\lambda_{j}^{*}\right)=1$. In such a case, the contractual distortions are equal for both organizations, and $S h_{-} i n t r a_{i j}=1 / 2$. (Organizational choices are made on the basis of the $a_{m j z}$ 's.) The share of intra-firm trade for any pair of countries $(i, j)$ increases monotonically with $\lambda_{j} \in(0,1)$, taking values in the interval $\left(0,\left.\Gamma_{i j}\right|_{\lambda_{j}=1} ^{\frac{(1-\alpha) \theta}{(1-\beta) \alpha}} /\left(1+\left.\Gamma_{i j}\right|_{\lambda_{j}=1} ^{\frac{(1-\alpha) \theta}{(1-\beta) \alpha}}\right)\right)$. A similar prediction arises from the extensions presented in Section 2.3, as we show in the Online Appendix.

\subsection{Empirical predictions and implementation}

Our theoretical model delivers predictions relating the bargaining power of workers to the internalization decision of individual global producers, highlighting heterogeneity according to the capital intensity of the technology. Internalization decisions by firms located in France and importing from country $c$ are governed by the function $\Gamma_{i c}$ (and the corresponding versions derived in Section 2.3 that we provide in the Online Appendix). $\Gamma_{i c}$ depends on the relative power of firms and workers in collective bargaining at the country level $\left(\lambda_{c}\right)$, the capital intensity of the buyer industry $\left(\beta_{i(n)}\right)$, its demand elasticity $\left(\alpha_{i(n)}\right)$, and the bargaining power of the final producer $\left(\phi_{c}\right)$. Let us write a stochastic version by adding an error term $\mu_{i s c}=\theta_{s}+\delta_{i}+\epsilon_{i s c} . \theta_{s}$ and $\delta_{i}$ are unobservable seller industry- and firm-specific effects, and $\epsilon_{i s c}$ is assumed to be i.i.d. with zero mean. Call $I_{i s c}$ a variable equal to 1 if firm $i$ imports from seller industry $s$ from an affiliate in country $c$, and zero if it imports from an independent supplier. The theory predicts:

\footnotetext{
${ }^{17}$ In a complete-contract setting, input expenditures are a share $(1-\beta) \alpha$ of revenues - see (4). In turn, revenues are a multiple $\frac{1}{1-\alpha}$ of operating profits, thus, input expenditure are a multiple $\frac{(1-\beta) \alpha}{1-\alpha}$ of operating profits.
} 


$$
I_{i s c}= \begin{cases}1 & \text { if } \Gamma\left(\lambda_{c}, \alpha_{i(n)}, \beta_{i(n)}, \phi_{c}, \epsilon_{i s c}\right)-1>0 \\ 0 & \text { if } \Gamma\left(\lambda_{c}, \alpha_{i(n)}, \beta_{i(n)}, \phi_{c}, \epsilon_{i s c}\right)-1 \leq 0\end{cases}
$$

In what follows we will use firm-level data to test the following empirical predictions:

Empirical Prediction 1 The likelihood of intra-firm imports at the firm - seller industry - exporting country level is decreasing in the bargaining power of workers in the exporting country.

Empirical Prediction 2 In industries characterized by relationship-specific investments, the effect of worker bargaining power on the likelihood of intra-firm imports should be stronger for capital-intensive industries. For industries where investments have outside value (non-specific), there should be no such differential effect.

Empirical Prediction 1 and Empirical Prediction 2 follow from Proposition 1 and Proposition 2 respectively (and from the equivalent Propositions discussed in Section 2.3, and presented in the Online Appendix.)

In practice we will estimate the following equation:

$$
I_{i s c}=\gamma W B P_{c}+\rho X_{c}+\theta_{s}+\delta_{i}+\epsilon_{i s c}
$$

where the dependent variable $I_{i s c}$ is defined as the share of intra-firm imports from seller industry $s$ and country $c$ by firm $i . W B P_{c}$ is the measure of the bargaining power of workers. Our theory predicts a negative sign for $\gamma$ : firms are expected to engage in less vertical integration and intra-firm trade when offshoring in destinations where labor market regulations enhance workers' bargaining power. $X_{c}$ are controls at the country level derived from previous literature. $\left\{\theta_{s}, \delta_{i}\right\}$ are respectively a full set of seller industry and firm dummies. (notice $\delta_{i}$ controls for the importer's (buyer) industry affiliation.) $\epsilon_{i s c}$ is an error term.

Equation (20) does not exactly correspond to equation (19). As discussed below, around $13 \%$ of the observations in our data have $0<I_{i s c}<1$. These correspond to firms importing from the same seller industry and country, but purchasing under both organizational forms. We choose to use $I_{i s c}$ as a share in order not to lose information coming from these "mixed" observations.

Identification of $\gamma$ comes from the variation in $W B P_{c}$ across countries. Our estimation equation includes a full set of firm- and seller industry-dummies. Firm dummies $\delta_{i}$ control for any individual firm characteristics that are constant across seller industries and countries and might systematically affect sourcing mode decisions (productivity, managerial preferences, etc.). ${ }^{18}$ They subsume the importer's industry affiliation, thereby controlling for $\alpha_{i(n)}$ and $\beta_{i(n)}$, as well as any other relevant characteristics of buyer industry. The inclusion of seller industry dummies $\theta_{s}$ holds constant any seller industry attributes (observable and unobservable) that might affect $I_{i s c}$. Our empirical strategy accounts for these compositional effects, exploiting within-firm changes in sourcing decisions across countries, with full controls for both buyer and seller industry characteristics.

\footnotetext{
${ }^{18}$ Feenstra and Hanson (2005) suggest $\phi$ might be firm-specific, in which case $\delta_{i}$ holds $\phi$ constant. If it varies at the seller industry-level (e.g., if inputs have varying degrees of relationship-specificity), $\theta_{s}$ control for it. If $\phi$ is determined by the country's institutions (e.g., FDI regulations) it is important to include a large number of institutional variables in $X$. Note that if $\lambda_{c}$ and $\phi_{c}$ are positively correlated that would work against us finding a significant effect of $W B P_{c}$.
} 


\section{Empirical Analysis}

This Section is composed of two parts. In the first part we describe the different datasets used in the implementation of the empirical analysis, providing further details in the Data Appendix. In the second part we report the empirical results.

\subsection{Data description}

\section{Firm-level data on global sourcing}

Our main dataset is the Enquete Echanges Internationaux Intra-Groupe produced by the French Office of Industrial Studies and Statistics (SESSI). It is based on a firm-level survey of manufacturing firms belonging to groups with at least one affiliate in a foreign country, and with international transactions totaling at least one million euro. The survey year is 1999.

The SESSI dataset provides, for each firm, details of all the international transactions carried out in 1999, including the industry where the product was produced (henceforth "Seller industry") and the country of origin. Seller industries are classified at the 4-digit level of the harmonized system (HS4). The survey provides the share of the value that was traded with affiliated firms versus independent firms. This information is detailed for each triplet of importing firm, seller industry, and exporting country. The trading partner is considered to be an affiliate when the group owns at least $50 \%$ of equity; thus, only cases where there is a relationship of control over the affiliate are considered. The firm's industry affiliation is provided at the 4-digit NAF 1993 level. The Nomenclature d'Activités Française 1993 corresponds closely to the 4-digit NACE Rev 1 Classification (although slightly more disaggregated), which is in turn close to the 4-digit ISIC Rev3 Classification. We will refer to each NAF code as the "Buyer industry." Carluccio and Fally (2012) use these data to study the link between sourcing modes and financial development. Corcos et al. (2013) and Defever and Toubal (2013) use it to test the predictions of property rights models of the multinational firm.

The data provide a good representation of the activity of international groups located in France. They account for around $82 \%$ of total trade flows by multinationals, and $55 \%$ and $61 \%$ of total French imports and exports, respectively. The dataset was crossed-referenced with alternative sources to check its validity. The trade flow data were found to be consistent with customs data and the intra-firm trade flows consistent with data on the location of French affiliates (INSEE's Financial Links Survey "LIFI," Bank of France and French General Treasury and Economic Policy Directorate - DGTPE - data). The data are very rich, but they have one potential drawback, common in survey data, which is non-response. If non-response is nonrandom, failing to correct for it might result in biased estimators. We do not believe this is a serious concern for our results. First, all of our results include firm dummies. Second, in all of our regressions we use an inverse probability-weighted estimator. Inverse probability weighting inflates the weights of observations belonging to firms that are underrepresented (e.g., small firms). ${ }^{19}$ Finally, Corcos et al. (2013) argue that the data might be potentially biased towards intra-firm because it includes only firms having at least one foreign affiliate. To correct for this potential bias, they complement the SESSI survey with comprehensive data on firm-level trade flows from the French Customs Office. As a third robustness check we report, in

\footnotetext{
${ }^{19}$ The SESSI provides the sampling probabilities, which are obtained with a Logistic model using as explanatory variables: trade flows; nationality of the controlling group; 2-digit sector classification; and an indicator of how many INSEE surveys the firm answers. More details can be made available from the authors upon request. See also Defever and Toubal (2013).
} 
the Data Appendix, the results obtained when applying their correction (along with more details on this methodology). ${ }^{20}$

\section{Data on worker bargaining power across countries}

Testing the model's implications calls for an empirical counterpart to $\lambda_{c}$; such empirical measure has been labeled $W B P_{c}$ in our main empirical equation (20). Important determinants of the balance of power between firms and workers are the regulations governing the labor markets. Industrial relations laws regulate relationships between firms and organized workers, providing the framework within which the bargaining process takes place.

The most comprehensive database on labor market regulations across countries is the one developed by Botero et al. (2004). These authors have assembled country-level data on three different categories of labor law for the year 1997. ${ }^{21}$ We use an index that measures the protection of employees engaged in collective disputes, which we label "Worker bargaining power" (it is the "Collective disputes index" in the Botero et al., 2004, database). It considers several aspects of labor law that determine the balance of power between employers and employees during industrial conflicts. These include whether the right to collective action is permitted by law, whether strikes are legal and, if so, the ease with which they can take place, and the extent to which employers can react with lockouts or by replacing striking workers. This index varies between 0 and 1, with higher values representing stronger bargaining power of workers. It provides an empirical proxy for $\left(1-\lambda_{c}\right)$. The Data Appendix provides more details.

Table 1 lists the countries used in the regressions, together with their index value. The table reveals a large variation that does not seem to be driven by any clear pattern, be it geographical or by per capita income level. The variation is remarkably strong across OECD countries, which represent an otherwise homogeneous group in terms of economic development and institutional quality. The sample median is 0.44 (std dev. 0.15). The median across OECD and non OECD countries is of 0.45 (std dev 0.12) and 0.42 (std dev 0.16), respectively. Labor market regulation varies a great deal across countries and development levels worldwide. We exploit this strong cross-country variation in our econometric analysis.

In robustness checks, we use the "Union power subindex," from the same source, which measures the statutory power and protection of trade unions, and the "Collective relations laws index," which is an average of both indexes. We also use data on labor market institutions from Nickell (2006) for a group of OECD countries (listed in the Data Appendix). We use the measure of union coverage, defined as the number of workers covered by collective agreements normalized on employment, for the year 1999. This measure has been commonly used as a proxy for union power (e.g., Hirsch, 1992). In a subset of regressions we restrict the analysis to imports from the US, and exploit variation in unionization rates and union coverage across industries within the US (the only country that releases detailed industry-level unionization data). The data come from the Current Population Survey (CPS) conducted by the US Census Bureau.

The Data Appendix provides a detailed description of the labor market data and other country-level variables, as well as their correlations (Table 7).

\footnotetext{
${ }^{20}$ We thank Giordano Mion for kindly sharing the codes to run this estimator.

${ }^{21}$ The data are available online at http://www.economics.harvard.edu/faculty/shleifer/files/labor_dataset_qje_dataforweb_20 05.xls. Previous works using these data include Tang (2012).
} 
Table 1: Worker bargaining power index by country (Botero et al., 2004)

\begin{tabular}{|c|c|c|c|c|c|}
\hline \multicolumn{6}{|l|}{ OECD } \\
\hline & Worker & bargaining power & & Worker & bargaining power \\
\hline$\overline{\text { Denmark }}$ & & 0.13 & Germany & & 0.50 \\
\hline Finland & & 0.21 & Hungary & & 0.50 \\
\hline Canada & & 0.25 & Ireland & & 0.50 \\
\hline Austria & & 0.29 & Netherlands & & 0.50 \\
\hline Korea & & 0.38 & New Zealand & & 0.50 \\
\hline Turkey & & 0.38 & Switzerland & & 0.50 \\
\hline UK & & 0.38 & Greece & & 0.54 \\
\hline US & & 0.38 & Japan & & 0.54 \\
\hline Belgium & & 0.42 & Mexico & & 0.58 \\
\hline Poland & & 0.42 & Norway & & 0.58 \\
\hline Australia & & 0.46 & Portugal & & 0.58 \\
\hline Spain & & 0.46 & Italy & & 0.83 \\
\hline Sweden & & 0.46 & & & \\
\hline \multicolumn{6}{|l|}{ Non-OECD } \\
\hline Jamaica & & 0.17 & Malaysia & & 0.38 \\
\hline Kenya & & 0.17 & Uruguay & & 0.38 \\
\hline Egypt & & 0.25 & Zimbabwe & & 0.46 \\
\hline Ghana & & 0.25 & Indonesia & & 0.50 \\
\hline Taiwan & & 0.25 & Venezuela & & 0.50 \\
\hline Zambia & & 0.25 & Bolivia & & 0.54 \\
\hline South Africa & & 0.38 & Colombia & & 0.54 \\
\hline Chile & & 0.33 & Singapore & & 0.54 \\
\hline Israel & & 0.33 & Argentina & & 0.58 \\
\hline Jordan & & 0.33 & Sri Lanka & & 0.58 \\
\hline Thailand & & 0.33 & Hong Kong & & 0.63 \\
\hline Tunisia & & 0.33 & India & & 0.63 \\
\hline Uganda & & 0.33 & Panama & & 0.63 \\
\hline Pakistan & & 0.33 & Senegal & & 0.63 \\
\hline Brazil & & 0.38 & Peru & & 0.71 \\
\hline China & & 0.38 & Ecuador & & 0.75 \\
\hline
\end{tabular}

\section{Estimating Sample}

We restrict the sample to importers that belong to manufacturing industries and import HS4 codes classified as manufactures (NACE Rev1 2-Digit codes 15 to 37). The Data Appendix provides further details of how the data was cleaned. ${ }^{22}$

Our empirical analysis focuses solely on imports from countries for which measures of labor market regulations and other country-level controls are available. The list of these countries is provided in Table 1. We obtain a baseline estimating dataset comprising 3,102 firms that import from 1,028 HS4 seller industries and 57 origin countries, including both developing and developed economies (see the Data Appendix). The average number of seller industries by firm is 10, with a standard deviation of 12 and a maximum of 164 .

\footnotetext{
${ }^{22}$ Importantly, we drop retailers. Also for consistency we exclude Tobacco (16) and Coke (23) industries, since, as pointed out by Antràs (2003) and Defever and Toubal (2013), sourcing modes in these industries are likely to be determined by other factors such as national sovereignty. All of our results are robust to their inclusion (they represent only 211 observations).
} 
The average firm imports from 7 countries (standard deviation 5) and the maximum number of countries by firm in the data is $37.84 \%$ of observations corresponds to firms importing the same industry code from at least two different countries. These features of the data allow us to exploit within-firm variation across countries in the econometric analysis. Table 2 provides summary statistics of the main variables used in the analysis.

Table 2: Summary statistics of main variables

\begin{tabular}{|c|c|c|c|c|c|}
\hline & Mean & $\begin{array}{l}\text { Std. } \\
\text { Dev. }\end{array}$ & Min & Max & Obs. \\
\hline \multicolumn{6}{|l|}{ Dependent variable } \\
\hline Share of intra-firm imports & 0.28 & 0.43 & 0 & 1 & 85,909 \\
\hline \multicolumn{6}{|l|}{ Labor market variables } \\
\hline Worker bargaining power & 0.44 & 0.15 & 0.13 & 0.83 & 57 \\
\hline Collective relations index & 0.43 & 0.13 & 0.19 & 0.71 & 57 \\
\hline Union power subindex & 0.43 & 0.19 & 0 & 0.71 & 57 \\
\hline Union coverage 1999 & 0.66 & 0.28 & 0.15 & 0.98 & 18 \\
\hline Labor rigidity index & 0.45 & 0.18 & 0.15 & 0.82 & 57 \\
\hline \multicolumn{6}{|l|}{ Country-level variables } \\
\hline (log) Capital endowment & 10.5 & 1.3 & 6.5 & 12 & 57 \\
\hline Trade openness & 68 & 14.4 & 24 & 90 & 57 \\
\hline FDI openness & 65.5 & 12 & 30 & 90 & 57 \\
\hline Rule of law & 0.65 & 0.20 & 0.3 & 0.97 & 57 \\
\hline (log) Skill endowment & 2.4 & 0.82 & 0.26 & 3.7 & 57 \\
\hline IPR protection & 364 & 83 & 174 & 487 & 57 \\
\hline Entry costs & 0.37 & 0.69 & 0 & 4.6 & 57 \\
\hline Creditors' rights & 1.9 & 1.2 & 0 & 4 & 57 \\
\hline Corporate tax & 31.3 & 5.8 & 15 & 45.1 & 57 \\
\hline
\end{tabular}

Notes: The dependent variable is the share of intra-firm imports at the firm - seller industry - exporting country level.

The baseline estimating dataset contains 85,909 firm - seller industry - exporting country cells with information on the share of intra-firm imports. Of these, $65 \%$ are pure outsourcing (share of intra-firm trade equal to zero), $22 \%$ are pure intra-firm (share of intra-firm trade equal to one) and $13 \%$ are a combination of both (share of intra-firm trade between zero and one). The average share of intra-firm trade by firm - seller industry - exporting country is 0.28 (standard deviation 0.43 ). Over half of the firms in the sample reports imports using both sourcing modes $(1,788)$.

\subsection{Worker bargaining power and intra-Firm trade: empirical results}

We start by confronting Empirical Prediction 1 to the data. We estimate equation (20) by ordinary least squares. It allows the inclusion of a large set of dummies and avoids the incidental parameter problem that arises with maximum likelihood estimation. (Results are similar using maximum likelihood techniques and keeping only observations taking values of either $0 \%$ or $100 \%$.) We proxy for the bargaining power of 
workers using the index developed by Botero et al.(2004) that was described in Section 4.1 above. $^{23}$

Table 3: Worker bargaining power and intra-firm trade

\begin{tabular}{|c|c|c|c|c|}
\hline \multirow[t]{2}{*}{ Dependent variable: } & \multicolumn{4}{|c|}{ Share of intra-firm imports } \\
\hline & $(1)$ & $(2)$ & $(3)$ & $(4)$ \\
\hline Worker bargaining power & $\begin{array}{l}-0.065^{* *} \\
(0.028)\end{array}$ & $\begin{array}{l}-0.102^{* * *} \\
(0.034)\end{array}$ & $\begin{array}{l}-0.108^{* * *} \\
(0.037)\end{array}$ & $\begin{array}{l}-0.108^{* * *} \\
(0.038)\end{array}$ \\
\hline Labor rigidity index & & & $\begin{array}{c}-0.060^{*} \\
(0.035)\end{array}$ & $\begin{array}{c}-0.061^{*} \\
(0.036)\end{array}$ \\
\hline Rule of law & & $\begin{array}{l}0.194^{* *} \\
(0.083)\end{array}$ & $\begin{array}{l}0.144^{*} \\
(0.082)\end{array}$ & $\begin{array}{l}0.150 \\
(0.095)\end{array}$ \\
\hline FDI openness & & $\begin{array}{l}0.002^{* *} \\
(0.001)\end{array}$ & $\begin{array}{l}0.002^{*} \\
(0.001)\end{array}$ & $\begin{array}{l}0.002^{*} \\
(0.001)\end{array}$ \\
\hline Trade openness & & $\begin{array}{l}-0.001 \\
(0.001)\end{array}$ & $\begin{array}{l}-0.001 \\
(0.001)\end{array}$ & $\begin{array}{l}-0.001 \\
(0.001)\end{array}$ \\
\hline Entry costs ( $\%$ of gdp) & & $\begin{array}{l}-0.018 \\
(0.058)\end{array}$ & $\begin{array}{l}-0.023 \\
(0.054)\end{array}$ & $\begin{array}{l}-0.022 \\
(0.054)\end{array}$ \\
\hline IPR protection & & $\begin{array}{l}0.000 \\
(0.000)\end{array}$ & $\begin{array}{l}0.000 \\
(0.000)\end{array}$ & $\begin{array}{l}0.000 \\
(0.000)\end{array}$ \\
\hline Creditor's rights & & $\begin{array}{l}-0.033^{* * *} \\
(0.007)\end{array}$ & $\begin{array}{l}-0.036^{* * *} \\
(0.006)\end{array}$ & $\begin{array}{l}-0.036^{* * *} \\
(0.006)\end{array}$ \\
\hline Corporate tax rate & & $\begin{array}{l}0.001 \\
(0.001)\end{array}$ & $\begin{array}{l}0.001 \\
(0.001)\end{array}$ & $\begin{array}{l}0.001 \\
(0.001)\end{array}$ \\
\hline Distance (weighted) & & $\begin{array}{l}0.000 \\
(0.000)\end{array}$ & $\begin{array}{l}-0.000 \\
(0.000)\end{array}$ & $\begin{array}{l}-0.000 \\
(0.000)\end{array}$ \\
\hline French speaking & & $\begin{array}{l}-0.049^{* * *} \\
(0.017)\end{array}$ & $\begin{array}{l}-0.062^{* * *} \\
(0.020)\end{array}$ & $\begin{array}{l}-0.062^{* * *} \\
(0.020)\end{array}$ \\
\hline Capital endowment & & $\begin{array}{l}-0.013 \\
(0.026)\end{array}$ & $\begin{array}{l}0.007 \\
(0.029)\end{array}$ & $\begin{array}{l}0.008 \\
(0.031)\end{array}$ \\
\hline Skill endowment & & $\begin{array}{l}-0.042^{* * *} \\
(0.015)\end{array}$ & $\begin{array}{l}-0.040^{* *} \\
(0.015)\end{array}$ & $\begin{array}{l}-0.040^{* *} \\
(0.015)\end{array}$ \\
\hline GDP per capita & & & & $\begin{array}{l}-0.004 \\
(0.034)\end{array}$ \\
\hline \# Clusters & 57 & 57 & 57 & 57 \\
\hline Seller industry dummies & Yes & Yes & Yes & Yes \\
\hline Firm dummies & Yes & Yes & Yes & Yes \\
\hline Observations & 85,909 & 85,909 & 85,909 & 85,909 \\
\hline R-squared & 0.599 & 0.604 & 0.604 & 0.604 \\
\hline
\end{tabular}

Notes: The regressions are OLS estimations of (20). The dependent variable is the share of intra-firm imports from seller industry $s$ from exporting country $c$ by firm $i$. Dummies by firm and seller industry and a constant are included in all specifications. "Worker bargaining power" measures the power and protection of workers during industrial conflicts. Both are obtained from Botero et al. (2004)- details are provided in the Data Appendix. "Labor Rigidity Index" is the "Employment Laws Index" from Botero et al. (2004). "Rule of law" is an index weighting variables capturing the perceptions of individuals about the enforcement of contracts from Kaufmann, Kraay and Mastruzzi (2003) in 1997 and 1998. "FDI openness" and "Trade openness" are from the Heritage Foundation. "Entry costs" measures of the cost of obtaining legal status to operate a firm (normalized by per capita GDP in 1999) from Djankov et al. (2002). "IPR Protection" in 2000 is drawn from Ginarte and Park (1997). "Creditor's rights" in 1999 comes from Djankov et al. (2007) and ranges from 0 (weak creditor rights) to 4 (strong creditor rights). "Corporate tax" is the top tax rate to corporations from World Tax database (U. of Michigan). "Distance" is between the biggest cities of any two countries, weighted by population from CEPII. "French speaking" equals one if French is the exporting country's official or national language. "Capital endowment" is the log of the stock capital per worker from the Penn World Tables. "Skill endowment" is the percentage of the population over age 25 with at least secondary education from Barro and Lee (2001). "GDP per capita" is the log of GDP per capita from the Penn World Tables. Heteroskedasticity-robust standard errors clustered by country are reported in parentheses. ${ }^{* * *},{ }^{* *}$, and ${ }^{*}$ indicate significance at the 1,5 , and 10 percent levels respectively.

\footnotetext{
${ }^{23}$ We next use alternative measures as robustness checks.
} 
Table 3 presents the results. Heteroskedasticity-robust standards errors are shown in parentheses. Given that $W B P_{c}$ varies across countries we cluster errors at the country level (see Moulton, 1986). In column (1) we run an univariate regression and obtain the expected sign. In the remaining two columns we add a large set of controls. Worker bargaining power has a negative and statistically significant effect, at the $1 \%$ confidence level, on the share of intra-firm imports. Take the estimate from column (4). Its interpretation is straightforward: going from the lowest value in the sample (Denmark, 0.13) to the highest (Italy, 0.83), reduces the share of intra-firm imports at the firm level by $10.8 \%$. Hence, if Italy had Denmark's collective bargaining institutions, the share of intra-firm exports to France would increase by $7,6 \%(0,108 \times(0.83-0.13))$. This effect is sizeable and economically meaningful, provided that the mean intra-firm share in the sample is of $28 \% .^{24}$

An empirically convenient fact is that labor market regulations tend to be uncorrelated with measures of economic and institutional development (see Table 7 in the Data Appendix). We nevertheless include as many controls as possible to make sure we are picking up the effect of $W B P_{c}$. Our measure of worker bargaining power is based on statutory laws and regulations. Regulations are effective as long as the law is enforced in the exporting countries. In column (2) we control for the general level of contract enforcement with the rule of law index taken from Kaufmann, Kraay and Mastruzzi (2003). This variable comes out positive and significant at the $5 \%$ level (although it losses some explanatory power when we enlarge the set of covariates in columns (3) and (4)). In column (3) we add the labor rigidity index from Botero et al. (2004). Although more rigid labor markets tend to discourage intra-firm trade, the effect of bargaining power is larger and statistically stronger.

The remaining controls, included in columns (2) to (4), confirm findings from previous studies. We include FDI and trade openness indicators from the Heritage Foundation. As expected, intra-firm import shares are higher from countries with policies favoring foreign investors. Openness to trade, however, is associated with larger values of arm's-length trade. Bernard et al. (2010) find qualitatively similar effects for US-based multinationals. We also add a measure of creditor's rights from Djankov et al. (2007) as it was shown in Carluccio and Fally (2012) that financial development provides incentives for outsourcing. In the same columns, we include the top corporate tax rate from the World Tax Database. In addition, we include the Ginarte and Park (2000) index of intellectual property rights protection (IPR). Investors might be more reluctant to outsource in countries with weak intellectual property rights' protection, an intuition not supported by the data. In columns (2) to (4) we address an important concern. Countries that impose tighter regulations on the labor markets might tend to actively regulate other aspects of economic life as well (Botero et al., 2004). Hence, the negative sign associated with the worker bargaining power variable might be picking up the effects of stricter overall regulatory systems. We control for the propensity to regulate firms' activities including a measure of the cost of obtaining legal status to operate a firm (normalized by per capita GDP in 1999), drawn from Djankov et al. (2002). As could be expected, this variable comes out negative and significant at the $1 \%$ level. Its inclusion does not affect the significance of the worker bargaining power index. We also include a dummy for French speaking country, and a measure of physical distance. Speaking the same language tends to encourage arm's-length relationships. We control for factor price differences using factor endowments. We obtain an imprecise estimate of the effect of the capital endowment. This is possibly due to the large measurement errors likely to plague this variable, and our

\footnotetext{
${ }^{24}$ In Denmark, over three-quarters of workers are union members, and the country's "Union power subindex" is $0,71$. Experts in the Danish labor market, however, classify the country as having one of the most flexible labor markets in the world (e.g., Hummels et al., 2014). In Table 4 we control for the "Union power subindex."
} 
clustering strategy. We also find that the effect of skill endowment is negative. Finally, in column (4) we control for GDP per capita.

The results are robust to the inclusion of an extensive set of controls related to the regulatory and institutional profiles of exporting countries.

\section{Sensitivity analysis: alternative samples and measures for $W B P_{c}$.}

Table 4 presents a series of robustness checks and extensions. All regressions include the full set of controls of column (4) in Table 3. The first column uses the "Collective relations laws" index from Botero et al. (2004), which has a stronger effect than our main measure. It is an average of our main variable and the "Union power subindex," that measures the statutory protection of trade unions. In column (2), we introduce both components in the same regression. The variables measure different aspects of collective bargaining, and both have the expected negative and significant sign. Interestingly, the inclusion of the "Union power subindex" increases the magnitude of $W B P_{c}$. The data suggests that enhanced rights to industrial action, as captured by $W B P_{c}$, are a more important determinant of sourcing modes than the rights related to forming labor unions.

Table 4: Worker bargaining power and intra-firm trade: sensitivity

\begin{tabular}{|c|c|c|c|c|c|c|c|}
\hline Dependent variable: & & & Share & f intra-firm & nports & & \\
\hline Sample: & Full & Full & OECD 18 & OECD & Switchers & Full & OECD \\
\hline & $(1)$ & $(2)$ & $(3)$ & $(4)$ & $(5)$ & $(6)$ & $(7)$ \\
\hline Collective relations index & $\begin{array}{l}-0.202^{* * *} \\
(0.058)\end{array}$ & & & & & & \\
\hline Worker bargaining power & & $\begin{array}{l}-0.148^{* * *} \\
(0.044)\end{array}$ & & $\begin{array}{l}-0.177^{* * *} \\
(0.033)\end{array}$ & $\begin{array}{l}-0.151^{* * *} \\
(0.052)\end{array}$ & $\begin{array}{l}0.056 \\
(0.043)\end{array}$ & $\begin{array}{l}-0.008 \\
(0.041)\end{array}$ \\
\hline Union power subindex & & $\begin{array}{l}-0.077^{* *} \\
(0.031)\end{array}$ & & & & & \\
\hline Union coverage 1999 & & & $\begin{array}{l}-0.228^{* * *} \\
(0.039)\end{array}$ & & & & \\
\hline$W B P_{c} \times$ int good dummy & & & & & & $\begin{array}{l}-0.205^{* * *} \\
(0.026)\end{array}$ & $\begin{array}{l}-0.215^{* * *} \\
(0.030)\end{array}$ \\
\hline \# Clusters & 57 & 57 & 18 & 25 & 57 & $\overline{57}$ & 25 \\
\hline Full set of country-level controls & Yes & Yes & Yes & Yes & Yes & Yes & Yes \\
\hline Seller industry dummies & Yes & Yes & Yes & Yes & Yes & Yes & Yes \\
\hline Firm dummies & Yes & Yes & Yes & Yes & Yes & Yes & Yes \\
\hline Observations & 85,909 & 85,909 & 76,488 & 79,881 & 63,986 & 85,909 & 79,881 \\
\hline R-squared & 0.604 & 0.604 & 0.628 & 0.621 & 0.461 & 0.610 & 0.627 \\
\hline
\end{tabular}

Notes: The regressions are OLS estimations of (20). The dependent variable is the share of intra-firm imports from seller industry $s$ and exporting country $c$ by firm $i$. Dummies by firm and seller industry and a constant are included in all specifications. "Worker bargaining power" measures the power and protection of workers during industrial conflicts. The "Union Power subindex" measures the statutory protection of trade unions. The "Collective Relations index" synthetically combines the "Worker bargaining power index" and the "Union Power subindex" using a simple average. The three variables are obtained from Botero et al. (2004)- details are provided in the Data Appendix. "OECD" includes all OECD members as of 1999. "OECD 18" includes OECD countries with data on union coverage (full list in the Data Appendix). "Switchers" includes only firms that report positive imports under both sourcing modes across countries and seller industries (1788 firms). "int good dummy" equals one if the seller industry is different from the buyer industry to which the firm belongs. All regressions include the full set of country-levels controls of column (4) in Table 3. Heteroskedasticity-robust standard errors clustered by country are reported in parentheses. ${ }^{* * *}$ indicates significance at the 1 percent level. 
In column (3) we use a traditional proxy for worker bargaining power which is union coverage, available for 18 OECD countries (listed in the Data Appendix). We next use two alternative subsamples. Column (4) includes only OECD countries (as of 1999). ${ }^{25}$ These countries constitute a homogeneous group in terms of economic development. They still display large variation in the collective bargaining index (mean of 0.45 and std. dev. of 0.14) enabling us to check if the results provided so far are not driven by broad differences in income or institutional development. ${ }^{26}$ In column (5), we restrict the estimating sample solely to firms that report positive imports under both sourcing modes across countries and seller industries ("Switchers"). The significant and large coefficient associated with the collective bargaining index alleviates concerns about our results being driven by firm self-selection into outsourcing. In columns (6) and (7) we interact $W B P_{c}$ with a dummy equal to one if the seller industry is different from the buyer industry. Around $78 \%$ of observations have "int good dummy" =1 (the definition follows the Feenstra and Hanson, 1999, criterion to measure intermediate goods, see the Data Appendix for details). Consistently with the model, results hold for more refined definitions of vertical production chains, even within the OECD.

In the Data Appendix we report the results obtained when applying the methodology developed in Corcos et al. (2013) to account for sample selection into the SESSI dataset. We also present, in the Online Appendix, a similar analysis to that in Table 3, with the dependent variable defined at the firm-country level. Our results carry through in both cases.

\section{Within-country evidence: exploiting variation across US industries.}

We complement the above results with within-country, cross-industry evidence. The US Census Bureau releases information on unionization rates across industries (classified with the Census Industry Classification CIC, comprising 82 manufacturing industries). Union membership and coverage are traditional proxies for worker bargaining power (Hirsch, 1992). Restricting to imports from the US, these data provide us with industry variation that completely controls for country-level characteristics. The US represents $11 \%$ of the value of imports in the data, and $8.7 \%$ of the number of transactions. The average share of intra-firm trade at the firm - seller industry level is 0.4, above the sample mean of 0.28 . The number of seller industries (HS4 products) is 589. Because of a lack of correspondence between HS4 and CIC codes, we aggregate the trade data at the HS3 level. We then map HS3 trade flows into CIC codes. (Details are provided in the Data Appendix.)

We regress the share of intra-firm imports from the US at the HS3 level on unionization of the CIC industries to which each HS3 product maps. We estimate:

$$
I_{H S 3_{-} u s}=\gamma(\text { Union membership })_{C I C \_u s}+\rho \text { Controls }_{C I C \_u s}+\eta \operatorname{tariffs}_{H S S_{\_} u s}+\epsilon_{H S 3_{-} u s}
$$

where $I_{H S 3 \_u s}$ is the share of intra-firm imports from the US at the HS3 level, (Union membership) $)_{C I C \_u s}$ proxies for worker bargaining power at the industry level. We include a vector of industry-level (CIC) controls as well as ad-valorem tariffs imposed in the EU on US exports at the HS3 level. $\epsilon_{H S 3_{-} u s}$ is an error term.

Table 5 provides the results. Given that CIC codes encompass several HS3 products, we cluster standard errors at the CIC level. In line with the cross-country evidence, worker bargaining power discourages intra-

\footnotetext{
${ }^{25}$ Excluding the Czech Republic and Iceland because they are not included in the Botero et al. (2004) dataset.

${ }^{26}$ The negative relationship between intra-firm trade and $W B P_{c}$ holds for the subsample of non-OECD countries, but the small number of observations prevents us from developing a detailed econometric analysis.
} 
firm trade. The set of industry-level controls include factor intensities, the ratio of value added to total industry shipments (measuring average vertical integration), the share of differentiated goods in total production, and a measure of ad-valorem EU-US tariffs. Union membership is significant at the $1 \%$ level in all four specifications. In column (4), we use union coverage instead (due to the US legislation, their correlation is of 0.99 ). In column (5), the dependent variable is defined at the firm-seller industry level (including controls for firm size and labor productivity, both in logs).

Table 5: Unionization rates across US industries (imports from the US only)

\begin{tabular}{|c|c|c|c|c|c|}
\hline \multirow[t]{2}{*}{ Dependent variable: } & \multirow[b]{2}{*}{ (1) } & \multicolumn{3}{|c|}{ Share of intra-firm imports } & \multirow[b]{2}{*}{$(5)$} \\
\hline & & $(2)$ & $(3)$ & (4) & \\
\hline \multirow{2}{*}{ (Union membership) ${ }_{C I C \_u s}$} & $-0.011^{* * *}$ & $-0.012^{* * *}$ & $-0.012^{* * *}$ & & $-0.004^{* * *}$ \\
\hline & $(0.002)$ & $(0.003)$ & $(0.003)$ & & $(0.001)$ \\
\hline \multirow[t]{2}{*}{ (Union coverage) $)_{\text {CIC_us }}$} & & & & $-0.011^{* * *}$ & \\
\hline & & & & $(0.003)$ & \\
\hline \multirow[t]{2}{*}{$(\mathrm{k} / \mathrm{l})_{C I C_{-} u s}$} & & -0.014 & 0.012 & 0.004 & $-0.036^{* * *}$ \\
\hline & & $(0.031)$ & $(0.040)$ & $(0.041)$ & $(0.013)$ \\
\hline \multirow[t]{2}{*}{$(\mathrm{VA} / \text { shipments })_{\text {CIC_us }}$} & & & 0.367 & 0.419 & 0.061 \\
\hline & & & $(0.355)$ & $(0.356)$ & $(0.091)$ \\
\hline \multirow[t]{2}{*}{$(\mathrm{h} / \mathrm{l})_{C I C \_u s}$} & & -0.098 & $-0.141^{*}$ & -0.126 & 0.003 \\
\hline & & $(0.069)$ & $(0.077)$ & $(0.079)$ & $(0.034)$ \\
\hline \multirow[t]{2}{*}{$\mathrm{Av} \_s p e c_{C I C \_u s}$} & & & 0.044 & 0.043 & $0.049^{*}$ \\
\hline & & & $(0.056)$ & $(0.056)$ & $(0.025)$ \\
\hline \multirow[t]{2}{*}{ EU-US tariffs (HS3) } & & & -0.131 & -0.140 & $-0.636^{* *}$ \\
\hline & & & $(0.243)$ & $(0.249)$ & $(0.238)$ \\
\hline \# Clusters & 50 & 50 & 50 & 50 & 50 \\
\hline Observations & 162 & 162 & 162 & 162 & 4,140 \\
\hline R-squared & 0.124 & 0.138 & 0.151 & 0.143 & 0.047 \\
\hline
\end{tabular}

Notes: The regressions are OLS estimations of (21). The dependent variable is a weighted share of intra-firm imports aggregated at the HS3 level of the seller industry, except in column (5) where it is defined at the firm-seller industry level. "Union

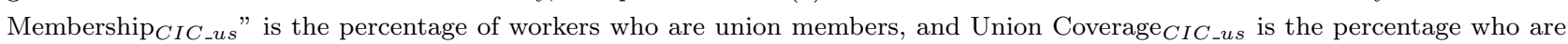

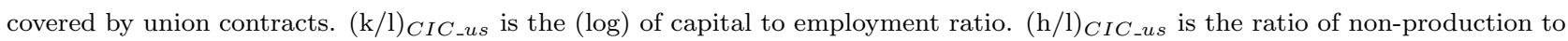
total workers. Av_spec IC_ $_{-}$s is the production-weighted average of the Rauch (1999) index. All sector variables are defined at the 3-digit CIC level. EU-US tariffs (HS3) are ad valorem tariffs imposed by the EU to the US. Sources and details are in the Data Appendix. Heteroskedasticity-robust standard errors clustered by CIC codes are reported in parentheses. ${ }^{* * *},{ }^{* *}$, and ${ }^{*}$ indicate significance at the 1,5 , and 10 percent levels respectively.

\section{Worker bargaining power, relationship-specific capital and intra-firm trade}

The theoretical analysis predicts capital intensity should only matter when capital is relationship-specific. We distinguish the industries where the importer's investments have relatively large value outside the relationship from those where this value is substantially lower. To obtain an empirical measure of specificity we use the measure developed in Rauch (1999). It classifies commodities according to whether they are sold 
on organized exchanges, referenced priced, or neither one of these. Goods sold in an organized exchange tend to be standardized and to have potentially many buyers and sellers ("thick" markets). On the contrary, goods that are not sold in organized exchanges tend to be differentiated and are traded in thinner markets. The value of standardized goods for a particular buyer-seller pair does not differ much from the value they have for other pairs of agents. Differentiation, however, tends to create a wedge between the value of a good inside a relationship and the value it has outside this particular relationship. Goods that are reference-priced lie in between these two cases. Nunn (2007) develops a measure of relationship-specific inputs based on these intuitions.

Using the Rauch classification we classify buyer industries into being "specific" or not, in the above sense. We also construct a measure of capital intensity at the buyer industry level - an empirical proxy for $\beta$ - based on firm-level data. Details of the construction of the variables are provided in the Data Appendix. Table OA2 in the Online Appendix shows intra-firm trade is increasing in the specific capital of the buyer industry, as predicted by the property rights theory of the firm. These results complement Nunn and Trefler (2013) and Antràs and Chor (2013), who use disaggregated data on different types of capital. Importantly, they imply that our measure is a good proxy for the relationship-specificity nature of the headquarter investments. The table also suggests that the relationship between capital intensity and intra-firm trade is less steep for the group of countries with high $W B P_{c}$.

\section{Results}

We now look into Empirical Prediction 2. We test whether the effect of worker bargaining power is heterogeneous according to the capital intensity of the buyer industry, indexed by $n$. We interact $W B P_{c}$ with two dummy variables. $\left((k / l)_{n}>\right.$ median) equals 1 if $(k / l)_{n}$ is above the sample median and zero otherwise, and $\left((k / l)_{n}<\right.$ median) equals 1 if $(k / l)_{n}$ is below the sample median and zero otherwise. We estimate the following equation, both for the complete sample and the sample consisting only of specific industries:

$$
I_{i s c}=\gamma_{1}\left(W B P_{c} \times(k / l)_{n}>\text { median }\right)+\gamma_{2}\left(W B P_{c} \times(k / l)_{n}<\text { median }\right)+\beta X_{c}+\theta_{s}+\delta_{i}+\epsilon_{i s c}
$$

We expect $\widehat{\gamma_{1}}<0, \widehat{\gamma_{2}}<0$ and $\left|\widehat{\gamma_{1}}\right|>\left|\widehat{\gamma_{2}}\right|$. The ranking implies that the likelihood of intra-firm imports is lower for country-industry pairs for which both capital intensity and worker bargaining power are large. Results are presented in Table 6. All regressions include the full set of country-level controls of column (4) in Table 3.

In the first column, we estimate (22) for the entire sample. In column (2), we re-estimate it for the subsample of specific industries (we recalculate the ranking of industries according to capital intensity for this subsample). ${ }^{27}$ In this case, $\widehat{\gamma_{1}}$ is larger than $\widehat{\gamma_{2}}$ in absolute values. The reduction in the share of intra-firm trade that is due to $W B P_{c}$ is larger for the capital-intensive industries. From column (3) onwards all regressions include a full set of interactions of GDP per capita with buyer industry dummies, following Nunn and Trefler (2014). We also add interactions between $W B P_{c}$ and buyer industry controls, which the literature has identified as determinants of intra-firm trade. These are: a measure of elasticity of demand taken from Broda et al. (2006) (see Antràs and Chor, 2013), a measure of dispersion constructed using comprehensive firm-level data for French manufacturing (see e.g., Antràs and Helpman, 2004), and

\footnotetext{
${ }^{27}$ The number of clusters is reduced because there are no imports in relationship-specific buyer industries from the following three countries: Kenya, Senegal and Uganda.
} 
Table 6: Worker bargaining power, specificity and capital intensity

\begin{tabular}{|c|c|c|c|c|c|c|}
\hline \multirow{3}{*}{$(k / l)_{n}$ measured with: } & \multirow{3}{*}{$\begin{array}{l}\text { Full Sample } \\
(1) \\
\end{array}$} & \multicolumn{5}{|c|}{$\begin{array}{c}\text { Relationship-Specific Industries } \\
\end{array}$} \\
\hline & & \multicolumn{2}{|c|}{ French data } & & \multicolumn{2}{|l|}{ US data } \\
\hline & & $(2)$ & $(3)$ & $(4)$ & $(5)$ & $(6)$ \\
\hline$W B P_{c} \times\left((k / l)_{n}>\right.$ median $)$ & $\begin{array}{l}-0.102^{* *} \\
(0.041)\end{array}$ & $\begin{array}{l}-0.133^{* * *} \\
(0.047)\end{array}$ & $\begin{array}{l}-0.150 * * \\
(0.057)\end{array}$ & $\begin{array}{l}-0.150^{* *} \\
(0.057)\end{array}$ & $\begin{array}{l}-0.155^{* *} \\
(0.060)\end{array}$ & \\
\hline$W B P_{c} \times\left((k / l)_{n}<\right.$ median $)$ & $\begin{array}{l}-0.115^{* * *} \\
(0.038)\end{array}$ & $\begin{array}{c}-0.082^{*} \\
(0.046)\end{array}$ & $\begin{array}{l}-0.094 \\
(0.065)\end{array}$ & $\begin{array}{l}-0.094 \\
(0.065)\end{array}$ & $\begin{array}{l}-0.106 \\
(0.083)\end{array}$ & \\
\hline$W B P_{c} \times$ Elasticity of Demand & & & $\begin{array}{l}0.001 \\
(0.002)\end{array}$ & $\begin{array}{l}0.001 \\
(0.002)\end{array}$ & $\begin{array}{l}0.001 \\
(0.002)\end{array}$ & \\
\hline$W B P_{c} \times$ Buyer Tariffs & & & $\begin{array}{l}0.007 \\
(0.008)\end{array}$ & $\begin{array}{l}0.007 \\
(0.008)\end{array}$ & $\begin{array}{l}0.009 \\
(0.010)\end{array}$ & \\
\hline$W B P_{c} \times$ Buyer Dispersion & & & $\begin{array}{l}-4.205^{* *} \\
(2.026)\end{array}$ & $\begin{array}{l}-4.205^{* *} \\
(2.026)\end{array}$ & $\begin{array}{l}-3.914^{*} \\
(2.292)\end{array}$ & \\
\hline GDP p.c. $\times\left((k / l)_{n}<\right.$ median $)$ & & & & $\begin{array}{l}-0.039 \\
(0.037)\end{array}$ & & \\
\hline GDP p.c. $\times\left((k / l)_{n}>\right.$ median $)$ & & & & $\begin{array}{l}-0.047 \\
(0.031)\end{array}$ & & \\
\hline GDP per capita & $\begin{array}{l}-0.007 \\
(0.032)\end{array}$ & $\begin{array}{l}-0.002 \\
(0.033)\end{array}$ & $\begin{array}{l}-0.039 \\
(0.037)\end{array}$ & & $\begin{array}{l}-0.031 \\
(0.036)\end{array}$ & $\begin{array}{l}-0.003 \\
(0.033)\end{array}$ \\
\hline$W B P \_c$ & & & & & & $\begin{array}{l}-0.107^{* *} \\
(0.044)\end{array}$ \\
\hline \# Clusters & 57 & 54 & 54 & 54 & 53 & 54 \\
\hline GDP $\times$ buyer industry dummies & No & No & Yes & Yes & Yes & No \\
\hline Full set of country-level controls & Yes & Yes & Yes & Yes & Yes & Yes \\
\hline Seller industry dummies & Yes & Yes & Yes & Yes & Yes & Yes \\
\hline Firm dummies & Yes & Yes & Yes & Yes & Yes & Yes \\
\hline Observations & 85,725 & 58,976 & 53,025 & 53,025 & 47,267 & 58,976 \\
\hline$R^{2}$ & 0.537 & 0.542 & 0.556 & 0.556 & 0.560 & 0.542 \\
\hline
\end{tabular}

Notes: The regressions are OLS estimations of (22). WBP is "Worker bargaining power." It measures the power and protection of workers during industrial conflicts, from Botero et al. (2004)- details are provided in the Data Appendix. $(k / l)_{n}$ is the 4-digit NAF median of firm level $(\log )$ ratio of the capital stock to total employment. $\left((k / l)_{n}>\right.$ median) equals 1 if $(k / l)_{n}$ is above the sample median and zero otherwise, and $\left((k / l)_{n}<\right.$ median $)$ equals 1 if $(k / l)_{n}$ is below the sample median and zero otherwise. "Relationshipspecific industries" is the subsample of industries with $S p e c_{n}=1$. Spec $n$ is a binary variable that equals 1 if the 4-digit industry is classified as specific (see the Data Appendix for details). "Elasticity of demand" comes from Broda et al. (2006). "Buyer Tariffs" is the import-weighted tariff from WITS at the buyer industry level across all imports and sourcing countries. "Dispersion" is the coefficient of variation of the buyer industry constructed using detailed French firm-level data. Details of the sources and construction of these measures are provided in the Data Appendix. All regressions include the full set of country-levels controls of column (4) in Table 3. Heteroskedasticity-robust standard errors clustered by country are reported in parentheses. ${ }^{* * *},{ }^{* *}$, and ${ }^{*}$ indicate significance at the 1 , 5 , and 10 percent levels respectively.

a measure of trade costs built using import-weighted tariffs. Their inclusion increases the coefficients associated with the interactions of $W B P_{c}$ with the capital intensity measures, and somewhat reduces their significance levels. In column (4), we interact GDP per capita with the capital intensity dummies. In column (5), we measure capital intensity with US data, to avoid the possibility of endogeneity in the capital intensity measures. ${ }^{28}$ The values of $\widehat{\gamma_{1}}$ and $\widehat{\gamma_{2}}$ are remarkably similar to those obtained with French data. As a robustness check, column (6) restricts the sample to the specific industries but ignores the differential effect across $(k / l)_{n}$. The coefficient is very close to that in column (4) of Table 3. (For the subsample of

\footnotetext{
${ }^{28}$ The correlation between French and US capital data is of 0.70 . In column (5) we lose some observations because of the imperfect mapping between SIC87 and NAF codes in the Food industry (corresponding to ISIC Rev2 2-digit code 15), and this restriction implies that there are no observations for Ecuador.
} 
non-specific industries we obtain similar but noisier results - at the $5 \%$ level. They are reported in the Online Appendix, in Table OA1.)

Our estimates imply that, when evaluated at the sample mean of $0.44, W B P_{c}$ reduces the share of intra-firm imports by $7 \%$ in the capital-intensive industries, and by $4 \%$ in the labor-intensive ones. An

F-test rejects the null hypothesis of equality of $\widehat{\gamma_{1}}$ and $\widehat{\gamma_{2}}$ within a $5 \%$ confidence interval, providing support to Empirical Prediction 2.

\section{Concluding Remarks}

In this paper we present an empirical analysis linking the sourcing modes of multinationals located in France to the bargaining power of workers in countries from which these firms import. Our results show that the bargaining power of workers in exporting countries has a negative and economically meaningful effect on the share of intra-firm trade. They hold for different measures of bargaining power and are robust to the inclusion of a large set of controls. Furthermore, similar results are found when we exploit variation in worker bargaining power across US industries. Our estimations also indicate that the negative correlation between intra-firm imports and worker bargaining power increases with capital intensity, only for the subsample of relationship-specific industries.

We have motivated our analysis with a simple model of foreign sourcing under incomplete contracts. The theoretical predictions are as follows. First, firms engage in outsourcing when worker bargaining power is strong. Second, the relative profitability of outsourcing increases with capital intensity, when capital has no outside value. This second prediction contrasts with the theoretical predictions of models based purely on incomplete contracts between firms, which have hitherto been the focus of the literature.

Overall, our results argue for a novel perspective on the role of labor market institutions in shaping the international organization of production. 


\section{Theory Appendix}

\subsection{Solutions}

Efficient production: Using the revenue function (2) we have:

$$
\frac{\partial R}{\partial k}=\frac{\beta \alpha}{k} A^{1-\alpha}\left(\frac{k}{\beta}\right)^{\beta \alpha}\left(\frac{l}{1-\beta}\right)^{(1-\beta) \alpha} \quad \frac{\partial R}{\partial l}=\frac{(1-\beta) \alpha}{l} A^{1-\alpha}\left(\frac{k}{\beta}\right)^{\beta \alpha}\left(\frac{l}{1-\beta}\right)^{(1-\beta) \alpha}
$$

Setting $\frac{\partial R}{\partial k}=r$ and $\frac{\partial R}{\partial l}=\omega$ and solving the 2-equation system we find:

$$
k_{E}=\frac{\beta}{r} A \alpha^{\frac{1}{1-\alpha}}\left(r^{\beta} \omega^{1-\beta}\right)^{\frac{-\alpha}{1-\alpha}} \quad \quad l_{E}=\frac{(1-\beta)}{\omega} A \alpha^{\frac{1}{1-\alpha}}\left(r^{\beta} \omega^{1-\beta}\right)^{\frac{-\alpha}{1-\alpha}}
$$

Inserting back in (2) gives expression (4).

Vertical Integration: The ex-ante problem for $\mathrm{F}$ is described by the following program:

$$
\begin{aligned}
& \max _{k_{v}} \pi_{v}=R\left(k_{v}, l_{v}\right)-w_{v} l_{v}-r k_{v} \\
& \text { s.t. } \\
& w_{v}=(1-\lambda) R\left(k_{v}, l_{v}\right) \frac{1}{l_{v}}+\lambda \omega \\
& \frac{\partial R}{\partial l}=\omega \\
& R\left(k_{v}, l_{v}\right)=A^{1-\alpha}\left(\frac{k_{v}}{\beta}\right)^{\beta \alpha}\left(\frac{l_{v}}{1-\beta}\right)^{(1-\beta) \alpha}
\end{aligned}
$$

The first order condition is $\frac{\partial R}{\partial k}=\frac{r}{\lambda}$, where $\frac{\partial R}{\partial k}$ is given by (23). This expression, together with the second constraint in the maximization program, form a 2-equation system with solution $\left(k_{v}, l_{v}\right)$. Substituting in the third constraint gives revenues as provided in expression $(8)$ in the main text, and inserting $\left(k_{v}, l_{v}\right)$ in the first constraint gives the equilibrium wage $w_{v}$. The full expressions are:

$$
k_{v}=\frac{\beta \lambda}{r} A \alpha^{\frac{1}{1-\alpha}}\left(\left(\frac{r}{\lambda}\right)^{\beta} \omega^{1-\beta}\right)^{\frac{-\alpha}{1-\alpha}} \quad l_{v}=\frac{(1-\beta)}{\omega} A \alpha^{\frac{1}{1-\alpha}}\left(\left(\frac{r}{\lambda}\right)^{\beta} \omega^{1-\beta}\right)^{\frac{-\alpha}{1-\alpha}} \quad w_{v}=\frac{1-\lambda[1-(1-\beta) \alpha]}{(1-\beta) \alpha} \omega
$$

Inserting $\left(k_{v}, l_{v}, w_{v}\right)$ into the objective function we obtain expression (8) in the main text. Union utility is obtained by inserting $\left(w_{v}, l_{v}\right)$ into $U\left(w_{v}, l_{v}\right)=\left(w_{v}-\omega\right) l_{v}$.

We get: $U\left(w_{v}, l_{v}\right)=(1-\lambda)[1-(1-\beta) \alpha] A \alpha^{\frac{\alpha}{1-\alpha}}\left(\left(\frac{r}{\lambda}\right)^{\beta} \omega^{1-\beta}\right)^{\frac{-\alpha}{1-\alpha}}$

Outsourcing: The ex-ante problem for $\mathrm{F}$ is described by the following program:

$$
\begin{aligned}
& \max _{k_{o}} \pi_{o}=\phi R\left(k_{o}, l_{o}\right)-r k_{o} \\
& \text { s.t. } \\
& w_{o}=(1-\lambda)(1-\phi) R\left(k_{o}, l_{o}\right) \frac{1}{l_{o}}+\lambda \omega \\
& \frac{\partial R}{\partial l}=\frac{\omega}{(1-\phi)} \\
& R\left(k_{o}, l_{o}\right)=A^{1-\alpha}\left(\frac{k_{o}}{\beta}\right)^{\beta \alpha}\left(\frac{l_{o}}{1-\beta}\right)^{(1-\beta) \alpha}
\end{aligned}
$$

The first order condition is $\frac{\partial R}{\partial k}=\frac{r}{\phi}$, where $\frac{\partial R}{\partial k}$ is given by (23). This expression, together with the second constraint in the maximization program, form a 2-equation system with solution $\left(k_{o}, l_{o}\right)$. Substituting in 
the third constraint gives revenues as provided in expression (11) in the main text, and inserting $\left(k_{o}, l_{o}\right)$ in the first constraint gives the equilibrium wage $w_{o}$. The full expressions are:

$$
k_{o}=\frac{\beta \phi}{r} A \alpha^{\frac{1}{1-\alpha}}\left(\left(\frac{r}{\phi}\right)^{\beta}\left(\frac{\omega}{1-\phi}\right)^{1-\beta}\right)^{\frac{-\alpha}{1-\alpha}} \quad l_{o}=\frac{(1-\beta)(1-\phi)}{\omega} A \alpha^{\frac{1}{1-\alpha}}\left(\left(\frac{r}{\phi}\right)^{\beta}\left(\frac{\omega}{1-\phi}\right)^{1-\beta}\right)^{\frac{-\alpha}{1-\alpha}} \quad w_{o}=\frac{1-\lambda[1-(1-\beta) \alpha]}{(1-\beta) \alpha} \omega
$$

Inserting $\left(k_{o}, l_{o}\right)$ into the objective function we obtain expression (8) in the main text.

M's payoff is: $\pi_{o}^{M}=(1-\phi) R\left(k_{o}, l_{o}\right)-w_{o} l_{o}=\lambda(1-\phi)(1-(1-\beta) \alpha) A \alpha^{\frac{\alpha}{1-\alpha}}\left(\left(\frac{r}{\phi}\right)^{\beta}\left(\frac{\omega}{1-\phi}\right)^{1-\beta}\right)^{\frac{-\alpha}{1-\alpha}}$

Union utility is: $U\left(w_{o}, l_{o}\right)=(1-\lambda)(1-\phi)[1-(1-\beta) \alpha] A \alpha^{\frac{\alpha}{1-\alpha}}\left(\left(\frac{r}{\phi}\right)^{\beta}\left(\frac{\omega}{1-\phi}\right)^{1-\beta}\right)^{\frac{-\alpha}{1-\alpha}}$

\subsection{Proofs of Section 2.2}

The following proofs use the fact that, for any given function $f(x)=a^{b(x)}$ where $a$ is a constant and $b(x)$ a subfunction of the variable $x$, we have: $\frac{\partial f(x)}{\partial x}=a^{b(x)} \ln (a) \frac{\partial b(x)}{\partial x}$ (Property 1).

Proof of Lemma 1: $\frac{\partial \pi_{v}}{\partial \lambda}=\frac{1-(1-\beta) \alpha}{1-\alpha} \lambda^{\frac{\beta \alpha}{1-\alpha}}(1-\alpha) A \alpha^{\frac{\alpha}{1-\alpha}}\left(r^{\beta} \omega^{1-\beta}\right)^{\frac{-\alpha}{1-\alpha}}>0$

Proof of Proposition 1: Proposition 1 studies how F's choice of organization depends on $\lambda$. F chooses the organizational from that provides him with the highest payoff. Thus, he chooses vertical integration if $\pi_{v}(\lambda,)>.\pi_{o}($.$) , he chooses outsourcing if \pi_{v}(\lambda,)<.\pi_{o}($.$) and he is indifferent if \pi_{v}(\lambda,)=.\pi_{o}($.$) , where$ $\pi_{v}(\lambda,$.$) and \pi_{o}($.$) are given respectively in expressions (8) and (11) in the main text. Note that \pi_{o}($.$) does$ not depend on $\lambda$. Now let us define $\lambda^{*}$ as the value of $\lambda$ such that $\pi_{v}\left(\lambda^{*},.\right)=\pi_{o}($.$) . Solving we find:$

$$
\lambda^{*}(\beta, \phi, \alpha) \equiv\left[\frac{\phi(1-\beta \alpha)\left(\phi^{\beta}(1-\phi)^{1-\beta}\right)^{\frac{\alpha}{1-\alpha}}}{(1-\alpha)}\right]^{\frac{1-\alpha}{1-(1-\beta) \alpha}}
$$

Lemma 1 shows $\pi_{v}(\lambda,$.$) is an increasing function of \lambda$, and inspection of $\pi_{o}$ in (11) shows that it is independent of $\lambda$. It follows that $\pi_{v}(\lambda,)>.\pi_{o}($.$) for any \lambda>\lambda^{*}(\beta, \phi, \alpha)$ and that $\pi_{v}(\lambda,)<.\pi_{o}($.$) for any$ $\lambda<\lambda^{*}(\beta, \phi, \alpha)$. To complete the proof we need to show that $0<\lambda^{*}<1$. Inspection shows that $\lambda^{*}>0 \forall$ $\beta \in(0,1], \forall \phi \in(0,1), \forall \alpha \in(0,1)$. To prove $\lambda^{*}(\beta, \phi, \alpha)<1$ we follow the methodology in Antràs (2003, Appendix A). Define first a function $\Lambda(\beta, \phi, \alpha) \equiv \lambda^{* \frac{1-(1-\beta) \alpha}{1-\alpha}}$.

$$
\Lambda(\beta, \phi, \alpha)=\frac{\phi(1-\beta \alpha)}{(1-\alpha)\left(\phi^{\beta}(1-\phi)^{1-\beta}\right)^{-\frac{\alpha}{1-\alpha}}}
$$

We now show $\Lambda(\beta, \phi, \alpha)<1 \forall \beta \in(0,1], \forall \phi \in(0,1), \forall \alpha \in(0,1)$. which implies $\lambda^{*}(\beta, \phi, \alpha)<1 \forall$ $\beta \in(0,1], \forall \phi \in(0,1), \forall \alpha \in(0,1)$. First note that $\Lambda(\beta, \phi, 0)=\phi<1$. It then suffices to show that $\partial \Lambda(\beta, \phi, 0) / \partial \alpha<0 \forall \beta \in(0,1], \forall \phi \in(0,1)$. We have, using Property 1:

$$
\frac{\partial \Lambda(1, \alpha, \beta, \phi)}{\partial \alpha}=\frac{\phi}{(1-\alpha)^{2}\left(\phi^{\beta}(1-\phi)^{1-\beta}\right)^{-\frac{\alpha}{1-\alpha}}} \times
$$




$$
\left[-\beta(1-\alpha)-(1-\beta \alpha)\left(-\frac{\ln \left(\phi^{\beta}(1-\phi)^{1-\beta}\right)}{1-\alpha}-1\right)\right]
$$

Rearranging we find that $\frac{\partial \Lambda(1, \alpha, \beta, \phi)}{\partial \alpha}<0$ for:

$$
\ln \left(\frac{1}{\phi^{\beta}(1-\phi)^{1-\beta}}\right)>(1-\alpha) \frac{1-\beta}{1-\alpha \beta} \equiv z(\alpha)
$$

$z(\alpha)$ is a decreasing function of $\alpha$ with a maximum at $z(0): 1-\beta$. Hence, we need check if the condition above holds for $\alpha=0$ to prove that it holds $\forall \alpha \in(0,1)$. In linear form it writes:

$$
d(\beta, \phi) \equiv \beta \ln \phi-(1-\beta) \ln (1-\phi)+\beta>1
$$

We have $\frac{\partial d(\beta, \phi)}{\partial \beta}>0$ for $\phi<\frac{e}{e+1}$. Hence for $\phi<\frac{e}{e+1}$ we need to check if $d(1, \phi)>0$, which holds since $-\ln (\phi)+1>1 \forall \phi \in(0,1)$. And for $\phi>\frac{e}{e+1}$ we need to check if $d(1, \phi)<0$, which is also true since $-\ln (1-\phi)>1$ for $\phi>\frac{e}{e+1}$. Therefore, we have that $\frac{\partial \Lambda(1, \alpha, \beta, \phi)}{\partial \alpha}<0 \forall \phi \in(0,1), \forall \beta \in(0,1), \alpha \phi \in(0,1)$. Together with $\frac{\partial \Lambda(1, \alpha, \beta, \phi)}{\partial \alpha}=\phi$ this ensures that $\lambda^{*}(\beta, \phi, \alpha)<1$.

Proof of Proposition 2: Proposition 2 is the outcome of a comparative static analysis on the cutoff $\lambda^{*}(\beta, \phi, \alpha)$. The proof is done by straightforward but lengthy differentiation. It proves useful to re-write $\lambda^{*}(\beta, \phi, \alpha)$ as:

$$
\lambda^{*}(\beta, \phi, \alpha)=g(\beta)^{z(\beta)}
$$

With

$$
g(\beta)=\frac{\phi(1-\beta \alpha)\left(\phi^{\beta}(1-\phi)^{1-\beta}\right)^{\frac{\alpha}{1-\alpha}}}{(1-\alpha)} \quad z(\beta)=\frac{1-\alpha}{1-(1-\beta) \alpha}
$$

Partial differentiation of $\lambda^{*}(\beta, \phi, \alpha)$ with respect to $\beta$ gives:

$$
\frac{\partial \lambda^{*}(\beta)}{\partial \beta}=z(\beta) g(\beta)^{z(\beta)-1} \frac{\partial g(\beta)}{\partial \beta}+g(\beta)^{z(\beta)} \ln (g(\beta)) \frac{\partial z(\beta)}{\partial \beta}
$$

Where the second term is follows from the use of Property 1. Rearranging:

$$
\frac{\partial \lambda^{*}(\beta)}{\partial \beta}=g(\beta)^{z(\beta)-1}\left[z(\beta) \frac{\partial g(\beta)}{\partial \beta}+g(\beta) \ln (g(\beta)) \frac{\partial z(\beta)}{\partial \beta}\right]
$$

The sign of $\frac{\partial \lambda^{*}(\beta)}{\partial \beta}$ depends on the sign of $\left[z(\beta) \frac{\partial g(\beta)}{\partial \beta}+g(\beta) \ln (g(\beta)) \frac{\partial z(\beta)}{\partial \beta}\right]$ since $g(\beta)^{z(\beta)-1}>0$. Using Property 1 and collecting terms we have:

$$
\frac{\partial g(\beta)}{\partial \beta}=\frac{\alpha}{1-\alpha} \phi\left(\phi^{\beta}(1-\phi)^{1-\beta}\right)^{\frac{\alpha}{1-\alpha}}\left[\ln \left(\frac{\phi}{1-\phi}\right) \frac{1-\beta \alpha}{1-\alpha}-1\right]
$$

And deriving $z(\beta)$ with respect to $\beta$ :

$$
\frac{\partial z(\beta)}{\partial \beta}=-\frac{(1-\alpha) \alpha}{(1-\alpha+\beta \alpha)^{2}}
$$

Inserting in $\left[z(\beta) \frac{\partial g(\beta)}{\partial \beta}+g(\beta) \ln (g(\beta)) \frac{\partial z(\beta)}{\partial \beta}\right]$ and rearranging we obtain: 


$$
z(\beta) \frac{\partial g(\beta)}{\partial \beta}+g(\beta) \ln (g(\beta)) \frac{\partial z(\beta)}{\partial \beta}=\left(\frac{1-\beta \alpha}{1-\alpha}\right) \frac{1}{1-\alpha+\beta \alpha}\left[-\ln (1-\phi)-(1-\alpha) \ln \left(\frac{1-\beta \alpha}{1-\alpha}\right)\right]-1
$$

The expression above depends on $\phi$ in a simple way. First note that $z(\beta) \frac{\partial g(\beta)}{\partial \beta}+g(\beta) \ln (g(\beta)) \frac{\partial z(\beta)}{\partial \beta}=0$ requires:

$$
-\ln (1-\phi)=(1-\alpha)\left[\frac{1-\alpha+\beta \alpha}{1-\beta \alpha}+\ln \left(\frac{1-\beta \alpha}{1-\alpha}\right)\right]
$$

The LHS of (25) is a monotonically increasing function of $\phi$ taking values from 0 to $+\infty$ in the range $\phi \in[0,1]$. The RHS is a positive constant. It follows that there is a unique value of $\phi$ such that $z(\beta) \frac{\partial g(\beta)}{\partial \beta}+g(\beta) \ln (g(\beta)) \frac{\partial z(\beta)}{\partial \beta}=0$, and thus $\frac{\partial \lambda^{*}(\beta)}{\partial \beta}=0$. Call this threshold value $\phi^{*}$. It is given by $\phi^{*}(\alpha, \beta)=1-e^{-(1-\alpha)\left[\frac{1-\alpha+\beta \alpha}{1-\beta \alpha}+\ln \left(\frac{1-\beta \alpha}{1-\alpha}\right)\right]}$. For $\phi>\phi^{*}(\alpha, \beta)$, we have $\frac{\partial \lambda^{*}(\beta)}{\partial \beta}>0$, and for $\phi<\phi^{*}(\alpha, \beta)$, we have $\frac{\partial \lambda^{*}(\beta)}{\partial \beta}<0$. In Proposition 2 we have written for simplicity:

$$
b(\alpha, \beta)=(1-\alpha)\left[\frac{1-\alpha+\beta \alpha}{1-\beta \alpha}+\ln \left(\frac{1-\beta \alpha}{1-\alpha}\right)\right]
$$

To complete the proof, notice that $b(\alpha, \beta)>0, \forall \beta \in(0,1)$ and $\forall \alpha \in(0,1)$. Therefore $0<\phi^{*}(\alpha, \beta)<1$ for $\forall \beta \in(0,1)$ and $\forall \alpha \in(0,1)$. Finally, for completeness let us note that $\frac{\partial \phi^{*}(\alpha, \beta)}{\partial \beta}=e^{-b(\alpha, \beta)} \frac{\alpha(1-\alpha)}{(1-\beta \alpha)^{2}}(1-$ $\alpha(1-\beta))>0$ and $\frac{\partial \phi^{*}(\alpha, \beta)}{\partial \alpha}=e^{-b(\alpha, \beta)} \frac{\beta+\alpha\left(1-3 \beta+\beta^{2}\right)}{(1-\beta \alpha)^{2}(1-\alpha)}$. The sign of $\frac{\partial \phi^{*}(\alpha, \beta)}{\partial \alpha}$ is ambiguous and depends on the interaction between $\beta$ and $\alpha$.

\subsection{Section 3.1}

Setup: The utility function is $U=Q^{\gamma} y^{1-\gamma}$, with $Q=\left(\int_{x \in X} q(x)^{\alpha}\right)^{\frac{1}{\alpha}}$ where $X$ is the set of potential varieties and $0<\alpha<1$ which follows from the assumption that $\sigma>1$. The ideal price index associated with $Q$ is $P=\left(\int_{x \in X} p(x)^{-\frac{\alpha}{1-\alpha}}\right)^{-\frac{1-\alpha}{\alpha}}$. World income is $E=\sum_{j \in J} \omega_{j} L_{j}$. The production function is market-specific because the labor unit requirements of capital vary across importer countries $i$ and the labor unit requirements of the input vary $a_{m j z}$ across source countries $j$. Adapting (1) to incorporate the new parameters we obtain $q=\varphi\left(\frac{k}{a_{h i} \beta}\right)^{\beta}\left(\frac{m}{a_{m_{j z}}(1-\beta)}\right)^{(1-\beta)}$. Together with the demand function leads to expression (15) in the main text (where we have introduced the trade costs $\tau_{i j}$ ).

Recall that final-good producers first draw their sourcing productivity $a_{m j z}$ and then they choose the organizational form. We assume that $a_{m j z}$ is common knowledge. Using (15) we can compute operating profits by following closely the deviations in Section 2.2 (adding subscripts $(i, j, i j)$ when required and using $\omega_{i}$ instead of $\left.r_{i}\right)$. We obtain:

$$
\begin{aligned}
& \pi_{i j V}(\varphi)=A \alpha^{\frac{\alpha}{1-\alpha}}\left(\left(\omega_{i} a_{h i}\right)^{\beta}\left(\omega_{j} a_{m j z} \tau_{i j}\right)^{1-\beta}\right)^{\frac{-\alpha}{1-\alpha}} \varphi^{\frac{\alpha}{1-\alpha}} \lambda_{j}^{\frac{1-(1-\beta) \alpha}{1-\alpha}}(1-\alpha) \\
& \pi_{i j O}(\varphi)=A \alpha^{\frac{\alpha}{1-\alpha}}\left(\left(\omega_{i} a_{h i}\right)^{\beta}\left(\omega_{j} a_{m j z} \tau_{i j}\right)^{1-\beta}\right)^{\frac{-\alpha}{1-\alpha}} \varphi^{\frac{\alpha}{1-\alpha}} \phi_{j}(1-\beta \alpha)\left(\phi_{j}^{\beta}\left(1-\phi_{j}\right)^{1-\beta}\right)^{\frac{\alpha}{1-\alpha}}
\end{aligned}
$$

$$
\text { hence } \Upsilon_{i j V}=\lambda_{j}^{\frac{1-(1-\beta) \alpha}{1-\alpha}}(1-\alpha) \text { and } \Upsilon_{i j O}=\phi_{j}(1-\beta \alpha)\left(\phi_{j}^{\beta}\left(1-\phi_{j}\right)^{1-\beta}\right)^{\frac{\alpha}{1-\alpha}} \operatorname{giving} \Gamma_{i j}=\frac{\lambda_{j}^{\frac{1-(1-\beta) \alpha}{1-\alpha}}(1-\alpha)}{\phi_{j}(1-\beta \alpha)\left(\phi_{j}^{\beta}\left(1-\phi_{j}\right)^{1-\beta}\right)^{\frac{\alpha}{1-\alpha}}} \text {, }
$$

which is the counterpart to (13) (with subscripts added).

The role of $\beta$ : Although we have considered a model with one differentiated sector, it is straightforward 
to extend it to include a number of differentiated sectors and derive a sector-level expression for the share of intra-firm trade, equivalent to (18), but with a sector subscript. In that case, one could investigate the role of capital intensity, as done in the firm-level setup. Deriving the counterpart to Proposition 2 is cumbersome given that $\Gamma_{i j}$ enters $S h_{i} n t r a$ as an exponential function of $\beta$. Under an additional simplification we can easily show the intuitions about the role of $\beta$ carry on to Sh_intra. Assume that $\theta=\frac{(1-\beta) \alpha}{(1-\alpha)}$ so that (18) becomes $S h \_i n t r a a_{i j}=\frac{\Gamma_{i j}}{1+\Gamma_{i j}}$. We drop subscripts $(i j)$. We have $\Gamma(\lambda, \beta, \phi, \alpha)=\frac{\lambda^{\frac{1-(1-\beta) \alpha}{1-\alpha}}(1-\alpha)}{\phi(1-\beta \alpha)\left(\phi^{\beta}(1-\phi)^{1-\beta}\right)^{\frac{\alpha}{1-\alpha}}}$ see (13). First notice that $\frac{\partial S_{-} \_n t r a_{i j}}{\partial \beta}=\frac{\partial \Gamma_{i j} / \partial \beta}{\left(\Gamma_{i j}+1\right)^{2}}$.

Following very similar steps as in the previous proofs one can easily show that $\frac{\partial \Gamma \lambda, \alpha, \beta, \phi)}{\partial \beta}<0$ for $\phi>\frac{e^{x(\lambda, \beta, \alpha)}}{1+e^{x(\lambda, \beta, \alpha)}}$ with $x(\lambda, \beta, \alpha)=\frac{1-\alpha}{1-\alpha \beta}+\ln (\lambda) . \quad x$ is an increasing function of $\lambda$ with a maximum at $x(1, \beta, \alpha)=\frac{1-\alpha}{1-\alpha \beta}$. Since $\frac{e^{x(\lambda, \beta, \alpha)}}{1+e^{x(\lambda, \beta, \alpha)}}$ increases with $x, \phi>\frac{e^{x(1, \beta, \alpha)}}{1+e^{x(1, \beta, \alpha)}}$ is a sufficient condition for $\frac{\partial \Gamma(\lambda, \alpha, \beta, \phi)}{\partial \beta}<$ $0 \forall \lambda \in(0,1)$. This in turn implies that $\frac{\partial \text { Sh_intra }_{i j}}{\partial \beta}<0 \forall \lambda \in(0,1), \forall \beta \in(0,1)$ and $\forall \alpha \in(0,1)$. Thus, comparing two industries such that $\beta_{h}>\beta_{l}$, we have $\operatorname{Sh}_{-} \operatorname{intra}_{i j}\left(\beta_{l}\right)>\operatorname{Sh}_{-} i n t r a_{i j}\left(\beta_{h}\right) \forall \lambda \in(0,1), \beta \in$ $(0,1)$ and $\forall \alpha \in(0,1)$. As in the firm-level model the result requires a large enough value of $\phi$.

\section{Data Appendix}

\section{A: Data description}

Labor Market Indexes: The Worker Bargaining Power variable is the "Collective protection subindex" from Botero et al. (2004). It is constructed as the average of eight dummy variables that equal one: (1) if employer lockouts are illegal, (2) if workers have the right to industrial action, (3) if wildcat, political and sympathy/solidarity/secondary strikes are legal, (4) if there is no mandatory waiting period or notification requirement before strikes can occur, (5) if striking is legal even if there is a collective agreement in force, (6) if laws do not mandate conciliation procedures before a strike, (7) if third party arbitration during a labor dispute is mandated by law and (8) if it is illegal to fire or replace striking workers. The "Collective relations laws index," used in column (1) of Table 4 is the average of "Collective protection subindex" and the "Union power subindex." The latter is constructed as the average of seven binary variables that equal one: (1) if employees have the right to unionize, (2) if employees have the right to collective bargaining, (3) if employers have the legal duty to bargain with a union, (4) if collective contracts are extended to third parties by law, (5) if the law allows closed shops, (6) if workers, or unions, or both have a right to appoint members to the board of directors, and (7) if workers' councils are mandated by law.

In Table 4 we use union coverage in 1980 and 1999 from Nickell (2006) for 18 OECD countries. ${ }^{29}$ The "Labor Rigidity Index" is the "Employment Laws Index" from Botero et al. (2004).

Country-level controls: The "rule of law" variable is taken from Kaufmann, Kraay and Mastruzzi (2003). It weights a number of variables capturing the perceptions of individuals about contract enforcement. It covers the years 1997 and 1998. The log of capital stock per worker in 1999 is taken from the Penn World Tables and the measure of skill endowment is the percentage of the population aged over 25 with at least secondary education in 1999 drawn from Barro and Lee (2001). Trade and FDI openness are respectively the Trade Freedom and Investment Freedom indexes produced by Heritage Foundation for

\footnotetext{
${ }^{29}$ Australia, Canada, Belgium, Denmark, Finland, Germany, Japan, Ireland, Italy, Netherlands, New Zealand, Norway, Portugal, Spain, Sweden, Switzerland, United Kingdom, United States. The database also contains (other than France) Austria, for which there is no data for the selected variable.
} 
2000. "Trade freedom" is based on the trade-weighted average rate (main source the World Bank WDR) and on non-tariff barriers. "Investment freedom" measures equal treatment for foreign and domestic investors. Protection of intellectual property rights in 2000, is drawn from Ginarte and Park (1997). The top tax rate for corporations is provided by World Tax Database (University of Michigan). A caveat is that the information refers to taxes on domestic companies, and different rates might apply on foreign owned firms. We use it due to the lack of wide cross-country information on corporate taxes to foreign firms. Distance is taken from CEPII. It measures bilateral distances between the biggest cities of any two countries, those inter-city distances being weighted by the share of the city in the overall country's population. French speaking equals 1 when French is the exporting country's official or national languages and languages spoken by at least $20 \%$ of the population of the country. Entry costs is a measure of the cost of obtaining legal status to operate a firm (normalized by per capita GDP in 1999) taken from Djankov et al. (2002). It includes all identifiable official expenses (fees, costs of procedures and forms, photocopies, fiscal stamps, legal and notary charges, etc.). The company is assumed to have a start-up capital of ten times per capita GDP in 1999. The index of Creditor's rights in 1999 comes from Djankov et al. (2007) and ranges from 0 (weak creditor rights) to 4 (strong creditor rights). GDP per capita in 1999 comes from the Penn World Tables and it is the PPP Converted GDP per Capita at current prices. 


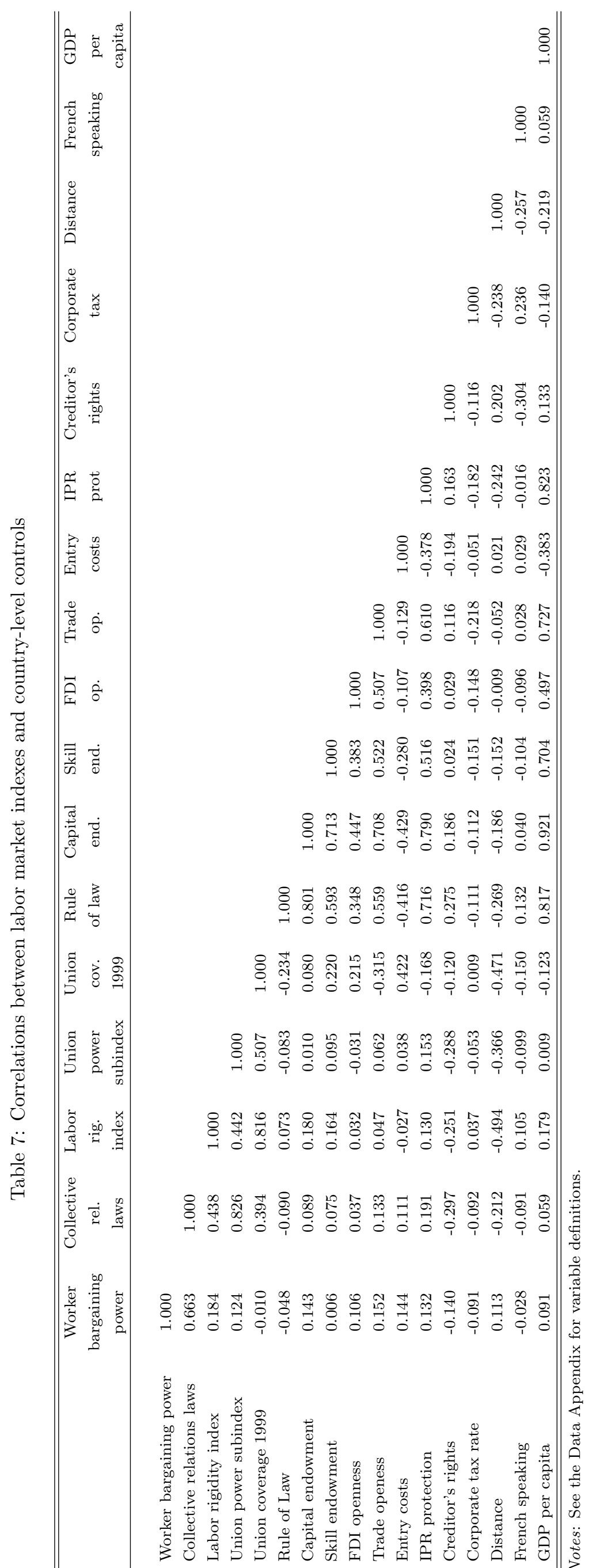




\section{Industry-level variables:}

Specificity: Our aim is to construct a measure of specificity at the 4-digit NAF industry level. We proceed as follows. First, we create a dummy equal to 1 if the 4-digit STIC4 rev2 commodity is classified as not being sold in organized exchange or reference-priced in Rauch's (1999) conservative classification. We then use a correspondence table from 4-digit STIC4 rev2 to HS4 (available in Jon Haveman's site). ${ }^{30}$ Finally, we use a concordance table from HS4 to 4-digit NAF (provided by the INSEE) to construct a 4-digit NAF level measure of relationship-specificity using production (from the SESSI dataset) as weights to obtain $A v_{-}$spec $_{n} \in[0,1]$. This measure has a mean of 0.66 (std. dev. 0.47). Its distribution is skewed to the left, with 169 industries having $A v_{-} s p e c_{n}=1$. Based on this, we classify those industries with $A v_{-} s p e c_{n}=1$ as specific, and those with $A v_{-}$spec $_{n}<1$ as non-specific. We use the most restrictive possible criteria in constructing this variable. Results hold if we lower the threshold, for example, using $A v \_s p e c_{n}>0.75$ as the criterion. We have originally 2824 -digit NAF industries in the sample. There are 23 4-digit NAF industries for which we could not map any 4-digit STIC4 rev2 commodity, and 5 with no information on capital intensity. Observations corresponding to these industries are dropped from the regressions in Table 6 and Table OA2 in the Online Appendix. The NAF codes are (the first two codes coincide with NACE Rev 1): 159Q 159L 173Z 201A 222E 223A 223C 262J 266E 266G 275A 275C 275E 275G 281C 282A 282B 284A 284B 284C 285A 285C 285D 287A 296A 333Z 371Z 372Z. For illustrative purposes, Table 8 provides a list of five industries with $A v_{-} s p e c_{n}=1$ and five with $A v_{-} s p e c_{n}<1$.

Table 8: Industry classification according to specificity: examples (NAF700 codes, 4-digit)

\begin{tabular}{l|l}
\hline $\begin{array}{c}\text { Classified as non-specific (average specificity }<1 \text { ) } \\
\text { Total number: 85 }\end{array}$ & \multicolumn{1}{c}{$\begin{array}{c}\text { Classified as specific (average specificity=1) } \\
\text { Total number: } 169\end{array}$} \\
\hline Code & Code \\
\hline \hline 151E Industrial production of meat products & 292A Ovens, furnaces and furnace burners manufacturing \\
$274 \mathrm{G}$ First processing of lead, zinc and tin & 295M Plastics and rubber machinery manufacturing \\
$265 \mathrm{E}$ Plaster manufacturing & 363Z Musical instruments manufacturing \\
$241 \mathrm{C}$ Dyes and pigments manufacturing & 300C Computers and peripheral equipment manufacturing \\
$171 \mathrm{~A}$ Spinning of cotton textiles & 286D Mechanical tool manufacturing \\
\hline \multicolumn{2}{c}{ Total number of industries with information on $(k / l)_{n}$ and specificity: 254} \\
\hline \hline
\end{tabular}

Notes: Author's calculation based on Rauch's (1999) commodity classification.

Capital intensity: Constructed using firm-level data from the EAE (Enquete Annuel d'Entreprises). It is an annually conducted survey that provides detailed firm-level data for all French firms with more than 20 employees whose main activity is in manufacturing. ${ }^{31}$ We first use the firms in the sample with available information on the capital stock to calculate the log of the ratio of the capital stock to total employment. The median of this firm-level measure is then calculated for each of the 254 4-digit NAF industries in our sample.

Intermediate good dummy: In Table 4 we use an "int good dummy" variable. The aim is to identify whether the buyer and the seller industries are different, in which case, this dummy equals 1 . As already explained, the buyer industries in our data are classified using the 4-digit NAF classification and the seller industries are classified using the HS system. To map HS4 codes into NAF codes we proceed as follows.

\footnotetext{
${ }^{30}$ There is no direct concordance between 4-digit STIC4 rev2 and the NAF or NACE classifications

${ }^{31}$ In spite of the size threshold the data remains highly representative. Eurostat reports that firms in the EAE accounted for around $87 \%$ of manufacturing production value in 1999 .
} 
Table 9: Capital intensity at industry-level (APE, 4-digit)

\begin{tabular}{|c|c|c|c|c|c|}
\hline \multicolumn{2}{|r|}{ Highest } & & Around the median & \multirow{2}{*}{\multicolumn{2}{|c|}{ Lowest }} \\
\hline Code & & Code & & & \\
\hline $158 \mathrm{~A}$ & $\begin{array}{l}\text { Industrial manufacture of } \\
\text { bread and fresh pastry }\end{array}$ & $287 \mathrm{P}$ & $\begin{array}{l}\text { Other metal objets manufac- } \\
\text { turing }\end{array}$ & $273 \mathrm{~J}$ & Ferroalloy production \\
\hline $151 \mathrm{~A}$ & $\begin{array}{l}\text { Processing and preserving of } \\
\text { meat }\end{array}$ & $286 \mathrm{D}$ & $\begin{array}{l}\text { Mechanical tool manufactur- } \\
\text { ing }\end{array}$ & $241 \mathrm{~N}$ & $\begin{array}{l}\text { Rubber products manufac- } \\
\text { turing }\end{array}$ \\
\hline $151 \mathrm{C}$ & $\begin{array}{l}\text { Processing and preserving of } \\
\text { poultry meat }\end{array}$ & $175 \mathrm{G}$ & Other textile industries & $265 \mathrm{~A}$ & Cement manufacturing \\
\hline $152 \mathrm{Z}$ & $\begin{array}{l}\text { Processing and preserving of } \\
\text { fish }\end{array}$ & $287 \mathrm{~L}$ & $\begin{array}{l}\text { Household metal objets } \\
\text { manufacturing }\end{array}$ & $265 \mathrm{C}$ & Lime manufacturing \\
\hline $151 \mathrm{E}$ & $\begin{array}{l}\text { Industrial production of } \\
\text { meat products }\end{array}$ & $294 \mathrm{D}$ & $\begin{array}{l}\text { Solding material manufac- } \\
\text { turing }\end{array}$ & $241 \mathrm{~A}$ & Industrial gas manufacturing \\
\hline
\end{tabular}

$\overline{\text { Notes: Source EAE. Industry capital intensity is calculated as the mean of the firm-level ratio of the capital stock to total }}$ employment (in logs).

We first concord each HS4 code in our sample to 4-digit CPA Rev1 codes (Classification of Products by Activity of the European Commision), which are equivalent to 4-digit NACE Rev 1.1 codes. We then use concord 4-digit NACE into 4 digit NAF codes using concordance tables from INSEE. In the few cases where a particular NACE mapped to more than one NAF code, we define it as intermediate good if the NACE code is different than all NAF codes it maps to.

Buyer industry controls: Buyer industry-level controls in Table 6 include the elasticity of demand, a measure of tariffs, and a measure of sales dispersion. The elasticity of demand comes from Broda et al. (2006). We use the demand elasticities for France which are presented at the HS3 level. We concord to 4-digit NAF codes using concordance tables provided by the INSEE. When more than one HS3 code mapped into the same 4-digit NAF codes we take a simple average. The tariff measure is constructed using applied tariffs from the Worldbank's WITS database. We use data from the French customs to identify imports flows at the HS6-country level for each of buyer industries. We average imports flows for 1996-1999, and use these averages to create weights associated with HS6. We then use the weights to create a trade-weighted average of tariffs for each 4-digit NAF code. The dispersion measure is the coefficient of variation, defined as the ratio of the standard deviation to the mean of sales at the buyer industry - level, multiplied by 100 (it is a scale-free measure). This measure is constructed from firm-level data using the quasi-exhaustive dataset BRN. We first take the average of total sales for each firm over the period 1996-1999, we then calculate both the standard deviation and the mean for each aggregate 4-digit NAF industry.

Firm-level variables: constructed from additional information present in the SESSI dataset. Size is the $\log$ of the nr. of employees and labor productivity is the log of value added divided by the nr. of employees. US data on industry unionization and factor intensities: Data on union membership (\% of workers who are union members) coverage (\% workers who are covered by union contracts) for 1999 for US manufacturing industries come from the Current Population Survey (CPS) conducted by the US Census Bureau. They are aggregated at the 3-digit CIC level (US Census Industry Classification, 82 manufacturing industries), which maps mostly into 3-digit 1987 SIC codes but sometimes 4- or 2-digit industries. The data were downloaded from www.unionstats.com. There is no concordance between HS4 and 4-digit SIC87 or the CIC classifications. We aggregate our HS4 trade data into HS3 codes and then map these flows into 4-digit SIC87 
codes using a concordance table provided by the US Census Bureau. Each SIC87 code maps into a single CIC code, though many SIC87 codes may map into the same CIC (i.e. a many-to-one mapping). Restricting to imports from the US we have 138 HS3 codes with positive flows. Out of these, 22 map into a single CIC industry (though possibly into more than one 4-digit SIC87 codes). The remaining 116 HS3 mapped into 2 4-digit SIC87 industries or more, which in turn mapped into different CIC codes. They were assigned SIC87 codes using data on US exports to France at 4-digit SIC level, produced by the US Census Bureau and available at Peter Schott's website: http://www.som.yale.edu/faculty/pks4/files/research/data/sic_naics_trade 20100504.pdf. First, SIC4 codes for which the Census reports a value of less than 50 thousand dollars were disregarded. Second, when a HS3 codes mapped into, for example, 3 SIC87 codes, we summed the values of exports of these 3 codes and calculated the percentage accounted for by each code in the group. Whenever a SIC87 code accounted for more than 75 percent of this value, we assigned the HS3 code to it. This gives us 88 HS3 codes mapped each into unique CIC codes. The correlation between intra firm trade and the probability of being assigned a particular code through this method is of $-0,02$. Finally, when a HS3 code mapped into SIC87 industries with similar trade values we assume it was imported from all of them under the same intra firm trade share. The underlying assumption of this procedure is that the structure of trade in the SESSI dataset is close to the structure of US-France trade (i.e. the SESSI is a representative survey of bilateral trade, as shown by the INSEE). We experimented with different thresholds and found similar results. The coefficient of a regression like the one in column (3) of Table 5 run on observations with a clear mapping is -.0154 (with t-stat -6.01), which is higher and even more significant.

Control variables come from the NBER productivity database website: http://www.nber.org/nberces/n bprod96.htm. They were downloaded originally in SIC4 codes and aggregated into CIC codes using a concordance table provided by the Census. $(\mathrm{h} / \mathrm{l})_{n(u s)}$ is the natural log of total capital stock to production workers. (h/l $)_{n(u s)}$ is the ratio of nonproduction to total workers. (VA/shipments) ${ }_{n(u s)}$ is the ratio of value added to total shipments. Ad valorem tariffs imposed by the EU to the US come from the BACI dataset available at CEPII. Tariffs are at the HS4 level. We aggregate at the HS3 level using imports from the US in the SESSI dataset as weights. Av_spec ${ }_{n(u s)}$ is the weighted average of the Rauch index, constructed as the measure Av_spec ${ }_{n}$ described above. It was aggregated to HS3 using trade flows from the US in the SESSI dataset as weights. All concordance tables can be found online on Jon Haveman's website (http://www.macalester.edu/research/economics/page/haveman/trade.resources/tradeconcordances.html). Estimating sample: The SESSI survey was answered by 4305 firms (both exporters and importers). Of these, 4,249 record positive imports. We keep only manufacturing imports (ISIC 15 to 37), which reduces the number of firms to 4,204 . We drop observations that have France as origin country $(6,633)$, leaving 4,177 firms. We finally drop firms whose main industry affiliation is outside manufacturing (mainly retailers) or is in extractive industries (ISIC 23), leaving 3,128 firms. Of these, 26 firms import from countries with no data on country variables of column (2) of Table 3. Our estimating sample thus contains 3,102 firms.

Accounting for potential sample selection: We use the methodology of Corcos et al. (2013) to account for selection into the SESSI dataset. In a first stage, a Probit model is run on on the group of firms belonging to the survey target population, with the dependent variable equal to 1 if firm $i$ responded to the survey. Explanatory variables are the total value of imports, the number of imported industry codes, the number of origin countries, and 3-digit buyer industry dummies. The inverse mills ratio calculated 
from this regression is then used as a regressor in the second stage (see their paper for more details). Table 10 reports the results of a regression similar to the oone of column (4) in Table 3, but without the firm dummies. Column (1) has no firm controls. Column (2) includes (log) firm size, (log) labor productivity. Column (3) adds the inverse Mills (IM) ratio obtained from Corcos et al. (2013). The number of observations is slightly reduced due to the lack of firm-level data for 70 firms.

Table 10: Corcos et al. (2013) correction

\begin{tabular}{lccc}
\hline \hline Dependent variable: & \multicolumn{2}{c}{ Share of intra-firm imports } \\
\hline Worker bargaining power & $(1)$ & $(2)$ & $(3)$ \\
& $-0.080^{* *}$ & $-0.087^{* *}$ & $-0.078^{* *}$ \\
& $(0.036)$ & $(0.036)$ & $(0.036)$ \\
\hline \hline \# Clusters & 57 & 57 & 57 \\
Full set of country-level controls & Yes & Yes & Yes \\
Seller-industry dummies & Yes & Yes & Yes \\
Firm-level controls & No & size, labor productivity & IM, size, labor productivity \\
Observations & 84,394 & 84,394 & 84,394 \\
R-squared & 0.089 & 0.090 & 0.099 \\
\hline \hline
\end{tabular}

Notes: ${ }^{* *}$, indicates significance at the 5 percent level. 


\section{References}

[1] Antràs, P. (2003), "Firms, Contracts, and Trade Structure," Quarterly Journal of Economics, 118(4), 13751418.

[2] Antràs, P. (2014a) "Global Production: Firms, Contracts and Trade Structure," manuscript.

[3] Antràs, P. (2014b) "Grossman-Hart (1986) Goes Global: Incomplete Contracts, Property Rights, and the International Organization of Production," Journal of Law, Economics, and Organization 30(1), 118-175.

[4] Antràs, P. and Chor, D. (2013) "Organizing the Value Chain," Econometrica, 81(6), 2127-2204.

[5] Antràs, P. Fort, T. and Tintelnot, F. (2014), "The Margins of Global Sourcing: Theory and Evidence from U.S. Firms," mimeo, Harvard University.

[6] Antràs, P. and Helpman, E. (2004) "Global Sourcing," Journal of Political Economy, 112 (3).

[7] Antràs, P. and Yeaple, S. (2014), "Multinational Firms and the Structure of International Trade," in Handbook of International Economics, 4, 55-130.

[8] Barro, R. and Lee, (2001), "International Data on Educational Attainment: Updates and Implications," Oxford Economic Papers, 53, 541-563.

[9] Bernard, A. B., Jensen, J. B., Redding, S. J. and Schott, P. K., (2010), "Intra-Firm Trade and Product Contractibility," American Economic Review: Papers and Procedings, 2010, 100(2), 444-448.

[10] Botero, J., Djankov, S., La Porta, R. and Lopez-De-Silanes, F (2004), "The Regulation of Labor," The Quarterly Journal of Economics, 119(4), 1339-1382.

[11] Broda, C. and Weinstein, D.E., (2006) "Globalization and the Gains from Variety," The Quarterly Journal of Economics, 121(2), 541-585.

[12] Broda, C., J. Greenfield and Weinstein, D.E.,(2006), "From Groundnuts to Globalization: A Structural Estimate of Trade and Growth," NBER Working Paper No. 12512.

[13] Budd, J., Konings, J. and Slaughter, M. (2005), "Wages and International Rent Sharing in Multinational Firms," Review of Economics and Statistics, 87, 73-84.

[14] Carluccio, J. and Fally, T. (2012), "Global Sourcing under Imperfect Capital Markets," The Review of Economics and Statistics, 94(3), 723-739.

[15] Cahuc, P., Carcillo, S. and Zylberberg, A. (2014). "Labor Economics," MIT Press Books, The MIT Press, Second edition.

[16] Coase, R. (1937), "The Nature of the Firm" Economica 4:16, 386-405.

[17] Corcos, G., Irac, D., Mion, G. and Verdier, T. (2013), "The Determinants of Intra-Firm Trade: Evidence from French Firms," The Review of Economics and Statistics, 95 (3),825-838.

[18] Defever, F. and Toubal, F. (2013) "Productivity, Relationship-Specific Inputs and the Sourcing Modes of Multinationals, Journal of Economic Behavior and Organization 94, 245-357.

[19] Djankov, S., La Porta, R. Lopez-de-Silanes, F. and Shleifer, A. (2002), "The Regulation of Entry," Quarterly Journal of Economics, 117, 1-37.

[20] Fally, T. (2012), "Production Staging: Measurement and Facts," mimeo, UC Berkeley.

[21] Feenstra, R. and G. Hanson (1999), "The Impact of Outsourcing and High-Technology Capital on Wages: Estimates for the United States, 1979-1990," Quarterly Journal of Economics114(3), 907-40

[22] Feenstra, R. and G. Hanson (2005), "Ownership and Control in Outsourcing to China: Estimating the Property-Rights Theory of the Firm," Quarterly Journal of Economics 120(2), 729-761. 
[23] Ginarte, J. and Park, L. (1997), "Determinants of Patent Rights: A Cross-National Study," Research Policy, $26(3), 283-301$.

[24] Grout, P. (1984), "Investment and Wages in the Absence of Binding Contracts: a Nash Bargaining Approach," Econometrica 52, 449-60.

[25] Hirsch, B. (1992), "Union Coverage and Profitability among U.S. Firms," Review of Economics and Statistics, 73, 69-77.

[26] Hummels, D., Ishii, J. Yi, K.-M. (2001) "The Nature and Growth of Vertical Specialization in World Trade," Journal of International Economics, 54:1, 75-96.

[27] Hummels, D., Jorgensen, R. Munch, J.R. and Xiang, C. (2014) "The Wage Effects of Offshoring: Evidence from Danish Matched Worker-Firm Data," American Economic Review 104, 1597-1629.

[28] Kaufmann, D. Kraay, A. and Mastruzzi, M. (2003), "Governance Matters III: Governance Indicators for 1996-2002," Working Paper No. 3106, World Bank.

[29] Lommerud, K.E., Meland, F. and Straume, O. R. (2009), "Can Deunionization Lead to International Outsourcing?" Journal of Interntional Economics, 77, 109-119.

[30] Martins, P. and Yang, Y. "Globalised Labour Markets? International Rent Sharing across 47 Countries," British Journal of Industrial Relations forthcoming

[31] McDonald, I., and Solow, R. (1981), "Wage Bargaining and Employment." American Economic Review 71, 896-908.

[32] Moulton, B., (1986) "Random group effects and the precision of regression estimates," Journal of Econometrics, $32(3), 385-397$.

[33] Nickell, W. (2006), "The CEP-OECD Institutions Data Set (1960-2004)" CEP Discussion Papers dp0759, Centre for Economic Performance, LSE.

[34] Nunn, N. (2007), "Relationship Specificity, Incomplete Contracts and the Pattern of Trade," Quarterly Journal of Economics, 122(2), 569-600.

[35] Nunn, N. and Trefler, D. (2013), "Incomplete Contracts and the Boundaries of the Multinational Firm," Journal of Economic Behavior and Organization, 94(1), 330-344.

[36] Nunn, N. and Trefler, D. (2014), "Domestic Institutions as a Source of Comparative Advantage," in Gopinath G, Helpman E, Rogoff K Eds, Handbook of International Economics vol. 4 North Holland, 263-315.

[37] Rauch, A. (1999), "Networks Versus Markets in International Trade" Journal of International Economics 48, 7-35.

[38] Skaksen, J.R. (2004), "International Outsourcing When Labor Markets are Unionized," Canadian Journal of Economics, 37(1), 78-94.

[39] Skaksen, M.Y., Sørensen, J.R., (2001), "Should trade unions appreciate foreign direct investment," Journal of International Economics 55, 379-390.

[40] Tang, H. (2012) "Labor Market Institutions, Firm-specific Skills, and Trade Patterns," Journal of International Economics 87(2), 337-351.

[41] Tintelnot, F. (2014), "Global production with export platforms," mimeo Princeton University.

[42] Williamson, O. (1985), "The Economic Institutions of Capitalism," New York: Free Press.

[43] Zhao, L. (1995), "Cross-hauling direct foreign investment and unionized oligopoly," European Economic Review, 39, 1237-1253.

[44] Zhao, L. (2001), "Unionization, Vertical Markets, and the Outsourcing of Multinationals," Journal of International Economics, 55, 187-202. 